\title{
Combatiendo al arqueofurtivismo en España ${ }^{1}$
}

\section{Fighting archaeolooting in Spain}

La historia, propiamente dicha, del arqueofurtivismo en España se inició en 1911, al promulgarse la primera ley que obligó a disponer de autorización para poder realizar intervenciones arqueológicas. Sin embargo, los orígenes de esta actividad son mucho más antiguos. En el artículo se describen casos, ocurridos en España, asimilables al arqueofurtivismo actual y que sucedieron en las etapas denominadas prearqueofurtiva (orígenes-siglo xVIII) y protoarqueofurtiva (siglo xvIII-1911). Se sigue la evolución histórica describiendo la etapa propiamente arqueofurtiva (a partir de 1911) con especial hincapié en las medidas adoptadas para contrarrestarlo. Finalmente se realizan una serie de reflexiones y propuestas que implican tanto a las autoridades competentes como al colectivo de los arqueólogos.

Palabras clave: arqueofurtivismo, historia, legislación, proporcionalidad, formación, protocolos.
The history of archaeolooting in Spain began in 1911 with the adoption of the first law requiring authorisation to carry out archaeological interventions. The origin of the plunder of archaeological sites is nonetheless much older. The article describes former cases of archaeolooting taking place in Spain similar to those of today throughout the periods designated as prearchaeolooting (origins-18th century) and protoarchaeolooting (18th century to 1911). This is followed by a description of the historical evolution of current archaeolooting (after 1911) with a special emphasis on the measures to counteract it. Finally, this study offers a series of reflections and proposals which are of concern to both authorities and archaeologists.

Keywords: archaeolooting, history, legislation, proportionality, training, protocols.
1. Este artículo ha sido elaborado en el marco del Proyecto del "Programa estatal de Investigación, Desarrollo e Innovación $(\mathrm{I}+\mathrm{D}+\mathrm{i})$ Orientada a los Retos de la Sociedad", financiado por el Ministerio de Economía, Industria y Competividad, sobre "Protección penal de la naturaleza y los bienes culturales", ref.: DER2017-87943-R, de la Universitat Jaume I de Castelló. 
El arqueofurtivismo es la actividad que llevan a cabo las personas que realizan remociones y/o exploraciones, tanto en la superficie terrestre como en el subsuelo y/o medio subacuático, con la finalidad de descubrir, documentar, estudiar, investigar, recoger, extraer y/o comprobar la existencia de bienes arqueológicos, tanto muebles como inmuebles, sin la autorización ni el rigor científico correspondiente.

Dicha actividad implica la pérdida y/o destrucción, total o parcial, de estos bienes así como la alteración de su contexto y/o la afectación de todos o alguno de sus valores (integridad, antigüedad, singularidad...).

Para que la actividad pueda calificarse de arqueofurtiva, son imprescindibles los dos requisitos señalados: no disponer de autorización de acuerdo con lo establecido en la legislación vigente del lugar donde se lleva a cabo y no aplicar el método científico académicamente correcto para la realización de una intervención arqueológica. Hoy por hoy, en nuestro entorno, la doble exigencia de una autorización y de un rigor científico es reiterativa: la concesión de una autorización por parte de la administración competente conlleva una serie de controles que garantizan la rigurosidad científica de la intervención.

Sin embargo, no siempre ha sido así. En ocasiones, a pesar de intervenir científicamente, conforme a los cánones de la época en la que se ha llevado a cabo, no siempre se ha dispuesto de la preceptiva autorización. Las motivaciones pueden ser muchas, bien por falta de infraestructura o abandono de funciones por parte de las administraciones competentes, por necesidad de realizar una intervención de urgencia sin tiempo a gestionarlas o incluso como protesta por las políticas culturales. ${ }^{2}$ Dichas intervenciones obviamente son ilegales, debiéndose sancionar como tales proporcionalmente a lo ocurrido, pero no puede afirmarse que se haya producido expolio.

Por otra parte, es posible que a pesar de disponer de la preceptiva autorización la intervención se lleve a cabo con una metodología o finalidad que no pueda calificarse de científica ni de rigurosa. En la actualidad siguen habiendo países en los que la autorización no conlleva ningún control científico, sino más bien todo lo contrario. ${ }^{3}$ En todos estos casos, las intervenciones son legales pero conllevan un expolio.

2. Ejemplos son la intervención de urgencia realizada en el yacimiento romano de Can Xammar (Mataró, Barcelona) en 1987 y, en el mismo año, la controversia sobre el yacimiento prehistórico del Puig d’En Roca (Girona). En este último caso, la Generalitat y los directores de la excavación polemizaron sobre el lugar donde debían depositarse los materiales, provocando la retirada de la correspondiente autorización mientras los arqueólogos seguían excavando. De todos modos, debemos ser muy cautos en estas situaciones y analizar caso por caso para determinar si se trata o no de actividades arqueofurtivas.

3. Me refiero a lugares como el autodenominado y fallido estado islámico, donde la autorización para realizar excavaciones arqueológicas únicamente comportaba la obligación de entregar un alto porcentaje de los beneficios obtenidos en la venta de los artefactos extraídos. También a lugares como el estado norteamericano de La Florida que otorga concesiones sobre pecios a cambio de un porcentaje del $20 \%$ sobre los beneficios obtenidos, sin exigir la aplicación de ninguna metodología ni control arqueológico (Alay 2015: 21).
La búsqueda de "tesoros" ocultos es tan antigua como la misma Humanidad, afirmándose que actividades como el saqueo de tumbas constituyen el segundo oficio más viejo del mundo (Meyer 1999: 139; Rodríguez Temiño 2012: 69-70 y Alay 2015: 15). Sin embargo, estrictamente —conforme al contenido del concepto que acabamos de argumentar- no podemos hablar de arqueofurtivismo sin la existencia de una metodología que pueda calificarse de científica, ni de un marco legislativo que regule la concesión de las autorizaciones.

En cuanto a metodología científica en arqueología, difícilmente podemos referirnos a un período anterior al siglo XVI. Es a partir de entonces y durante los siguientes dos siglos cuando la arqueología se fue configurando hasta convertirse en "una disciplina consciente y científica” (Daniel 1986: 109).

En cuanto al marco legislativo, las fechas variarán en cada país. En España, no será hasta la entrada en vigor de la Ley de Excavaciones de 1911, en que por primera vez se establece -en su artículo 7- la obligatoriedad de disponer de autorización para poder realizar excavaciones arqueológicas (Alay 2015: 57-62).

Conforme a lo expuesto, el estudio del arqueofurtivismo español debería limitarse cronológicamente a lo acontecido a partir de 1911. En consecuencia, muchas conductas asimilables a las que hoy día calificamos como arqueofurtivas y cuyo análisis contribuiría notablemente a dicho estudio quedarían al margen. A fin de no renunciar al mismo me permití la licencia de proponer las denominadas etapas prearqueofurtiva (desde el origen mismo de la Humanidad hasta el siglo XVIII) y protoarqueofurtiva (desde el siglo XVIII hasta 1911) (Alay 2015: 25; Alay 2016: 33-36 y Alay 2018: 90).

\section{El prearqueofurtivismo}

La singular y espectacular arquitectura de los monumentos megalíticos, así como las numerosas leyendas sobre los tesoros que ocultan, ha motivado su expolio desde la antigüedad. En el dolmen de Puig Ses Lloses (Folgueroles, Barcelona) (Batista 1963) y en el de Mas Bousarenys (Santa Cristina d'Aro, Girona) (Esteva 1964), por ejemplo, se encontraron cerámicas ibéricas y romanas. Gran parte de las piezas recuperadas en la excavación del dolmen del Pla de la Fossa (Gargallà-Montmajor, Barcelona) eran de cronología medieval (Daura 1983).

Debemos ser cautelosos, sin embargo, al atribuir estos indicios al saqueo debiéndose contextualizar debidamente, ya que podrían corresponder en realidad a sus reutilizaciones como refugios de pastores y campesinos e incluso otras tan peculiares como la del dolmen de la Font dels Coms (Vall de BaiascaLlavorsí, Lleida) usado como horno en época romana (Antón 2007: 13).

En la necrópolis fenicia del Cerro de San Cristóbal de Almuñécar (Granada) - del siglo vII a. C. y conocida como "Laurita"-, las incineraciones estaban depositadas en vasos de piedra (Pellicer 1962 y 2007). Tres de ellos tienen inscritas las cartelas de faraones egipcios de la XXII dinastía (850-773 a. C.) y uno la del faraón Apofis I de la XV dinastía (1644-1537 a. 
C.). Con alguna excepción (Padró 1983: 157-158), la mayoría de autores (Molinero 1995: 234-235; Blázquez 1996: 552 y Velázquez 2002: 114) consideran que tanto estos vasos como otros que se han descubierto en la zona proceden del saqueo de las necrópolis reales egipcias.

Habiéndose descartado que se trate de falsificaciones o imitaciones con fines decorativos, entre las hipótesis más probables se señala que tras su robo, fueron adquiridos por los fenicios en la segunda mitad del siglo vIII a. C. Junto con otros objetos del mismo origen se depositaron en los palacios de Tiro y Sidón. Posteriormente una parte de estos tesoros se trasladaron a Cartago y mayoritariamente a las colonias fenicias de la costa andaluza donde los vasos se reutilizaron como urnas cinerarias (Pellicer 2007: 52). ${ }^{4}$

Podemos referirnos también al yacimiento denominado Sorres VIII en Gavà (Barcelona) (Alay 2015: 27-28). Se trata de los restos de un naufragio de época romana, aunque se encontrara en tierra firme. Se descubrió en los años sesenta del siglo pasado al realizar una extracción de áridos destinados a la construcción. Prácticamente todos los elementos de interés se repartieron entre los descubridores o fueron destruidos y la mayor parte del navío recubierta con ruina de obra. A pesar de ello, con el tiempo pudo determinarse el lugar y cronología aproximada.

Su datación planteó una cuestión diacrónica entre las diferentes piezas recuperadas o conocidas. Por un lado estaba el navío con un costillaje de madera forrado con planchas de plomo (con una cronología entre los siglos IV y I a. C.), tres anclas de hierro (posiblemente procedentes de este mismo barco y con una cronología a partir del siglo II a. C.), así como una campana de bronce tubular (a partir del siglo II a. C.) que databan el pecio entre los siglos II y I a. C. Por otro lado, estaban dos cascos etruscos con unas cronologías del siglo $\mathrm{V}$ a. C. el primero y entre los siglos IV y III a. C. el segundo.

Entre las diversas hipótesis que se barajaron para explicarlo, destacamos la posibilidad de que dichos cascos formaran parte del cargamento, siendo objeto de comercio como antigüedades. Aunque no fuera precisamente la más probable, nos interesa en cuanto de ser cierta testimoniaría el expolio de antiguas tumbas etruscas, ya en época romana, así como la existencia de un tráfico vinculado al mismo. Recordemos en este sentido los casos documentados del cónsul Lucio Mumio en el saqueo de Corinto (146 a. C.), los cargamentos de los pecios de Anticitera y Mahdia (ambos del siglo I a. C.) o las numerosas obras griegas de la Villa Adriana en Tívoli (II d. C.). No debería sorprendernos que algunos de los ricos

4. Esta hipótesis se fundamenta esencialmente en un vaso de alabastro con la cartela del faraón Takelot III —similar a los encontrados en Almuñécar- descubierto en Asur. Dicho vaso dispone de una inscripción cuneiforme informando que formaba parte del botín procedente del saqueo y destrucción del palacio de Sidón, llevado a cabo por el rey asirio Asaradón en el año 676 a. C. Teniendo en cuenta el mismo origen primigenio se apunta que los vasos encontrados en Andalucía salieron de Fenicia en un momento anterior al ataque asirio (Pellicer 2007: 52). propietarios de las numerosas villas distribuidas por todo el litoral mediterráneo coleccionaran también "objetos de arte".

Nos llaman también la atención los fragmentos de cerámica ática hallados en contextos visigodos del yacimiento de El Tolmo de Minateda (Hellín, Albacete). En su estudio, Lorenzo Abad y Victoria Amorós concluyen que "se trataría de un par de vasos de carácter destacado (al menos un ánfora) ubicados en un reducido espacio", apuntando la posibilidad de que conscientemente "se hubieran conservado durante algún tiempo, a manera de artículo de lujo, en el palacio episcopal”. Recuerdan además la similitud con la aparición de fragmentos de ánfora griega en un nivel islámico del siglo XI en el solar de L’Almoina, Valencia (Abad y Amorós 2017: 71).

Por nuestra parte, estos episodios nos llevan a sugerir que si efectivamente se llegara a constatar en futuras investigaciones un interés o necesidad por parte de determinados estamentos altomedievales y medievales en disponer de recipientes antiguos, no debería descartarse la posibilidad de un tráfico sobre los mismos. En este sentido, los antiguos expolios documentados en tantas necrópolis ibéricas no únicamente tendrían por objeto buscar materiales valiosos sino que, al menos en parte o además, podrían orientarse a la búsqueda de determinadas piezas. ${ }^{5}$

Jurídicamente se han destacado algunos fueros y partidas de Alfonso X El Sabio (1221-1264) como medidas pioneras en la protección del patrimonio histórico (Pérez 2012). En relación con las actividades arqueofurtivas, únicamente reseñaremos la Ley XLV, Título 28, de la Partida Tercera donde se regulan los hallazgos de tesoros. De hecho mantiene la regulación romana de los mismos, definida por Paulo y reformada por Adriano (Alay 2000: 36-37). No es por tanto novedosa, pero es el antecedente de su posterior regulación en el Código Civil.

Calificada también de pionera es la instrucción de Pedro el Ceremonioso (1319-1387) concediendo una guarnición armada al obispo de Megara para la custodia y defensa de la Acrópolis de Atenas, fechada en Lleida el 11 de septiembre de 1380. En la misma se hace un elogio al Partenón (Institut de Prehistòria i Arqueologia, 1980). No se refiere al arqueofurtivismo pero por primera vez se justifica - aunque no sea la principal finalidad- la intervención de hombres armados en la protección de un edificio expresamente descrito en las órdenes de artísticamente singular.

En los archivos de Queralbs (Barcelona) se conserva un documento según el cual la reina María de Castilla, esposa de Alfonso el Magnánimo (1396-1458), otorga en 1423 a Joan Saclota permiso para "cavar y buscar todos los tesoros supuestamente escondidos o encantados sin ningún impedimento”. Así mismo, en

5. Podríamos así mismo plantearnos las mismas cuestiones en relación con el espectacular conjunto de cerámicas áticas de los siglos IV-III a. C. halladas en la Cámara de Piquía (Arjona, Jaén), datada en el siglo I a. C. Referencia: Ruiz, A.; Molinos, M.; Risquez, C.; Gómez, F. y Lechuga, M. A. (2015). La cámara de Piquía, Arjona en A. Ruiz y M. Molinos. Jaén tierra íbera: 40 años de investigación y transferencia. Universidad de Jaén: 357-374. 
el año 1439, concedió a Antoni Pinya de Perpiñán permiso para buscar "tesoros y joyas de días antiguos, escondidos por cualquier lugar". Una vez más, los monumentos megalíticos fueron el objetivo prioritario de estas búsquedas (Fábrega 2000: 75-76 y 87).

Semejante es el caso del licenciado Pedro Vázquez de Orxas en Galicia. En 1609 el rey Felipe III le otorgó una real cédula para buscar los "tesoros de los Galigrecos" en las mamoas y castros gallegos, provocando un expolio masivo de yacimientos arqueológicos.

En ninguno de los dos casos podemos concluir que fueran actividades arqueofurtivas, puesto que disponían de autorización conforme la legislación entonces vigente, aunque el expolio fuera incuestionable. Distinto es, sin embargo, el caso del denominado Ciprianillo o gran libro de San Cipriano, que incluía una guía de los "tesoros que los moros escondieron bajo tierra cuando fueron expulsados por los cristianos" y provocaría otra oleada de expolios arqueológicos tanto en Galicia como en el norte peninsular a finales del siglo xVIII y principios del xIX (Pena y Díaz 2018: 245-246).

\section{El protoarqueofurtivismo}

Durante el siglo XVIII se produce, en el conjunto del Estado español, la primera plasmación normativa reconocida sobre Patrimonio Histórico. Será "la base y punto de partida de tota la elaboración teórica posterior" y "se empieza a asentar una estructura jerarquizada (Corona, Academias, etc.), una delimitación competencial "piramidal» indispensable per fijar el marco de actuación práctica de la normativa" (Quirosa 2006: 16-17).

Como factores decisivos, han sido apuntados la difusión del pensamiento ilustrado y el cambio dinástico de la monarquía.

El primero aportó un creciente interés por el estudio del pasado y la proliferación de los viajeros ilustrados, valga la redundancia (Quirosa 2006: 6-8). También se llevan a cabo los primeros estudios (Teatro Romano de Sagunt, 1705) e intervenciones arqueológicas (Cartama, Málaga, 1747; Clunia, 1774...) entre las que destacaron las de Itálica, en Sevilla (entre 1781 i 1788).

Por su parte, los Borbones exportaron las políticas culturales que desde hacía tiempo se estaban llevando a término en Italia, así como la influencia academicista francesa. Durante el siglo se crearán la Real Academia de la Historia (1739) y la Real Academia de San Fernando (1744) (Buscató 2011: 29). También debe considerarse la influencia de las primeras intervenciones en Herculano (1738) y Pompeya (1748), dirigidas por el aragonés Roque Joaquín de Alcubierre (1702-1780) y patrocinadas por el rey Carlos III (entre 1759 y 1788), propietario de la finca donde se localizó la ciudad de Herculano.

Sin embargo, las aportaciones normativas del siglo XVIII son dispersas y poco homogéneas, actuando sobre ámbitos muy concretos. Por ejemplo una Instrucción, conservada en el Archivo de Simancas, del marqués de la Ensenada a Francisco Barrero Peláez, intendente de Marina del Departamento de Cartagena, cursada como Real Orden del 8 de abril de 1752, sobre "la protección y conservación de antigüedades que se hallaren al hacer obras en puertos", las cuales debían enviarse a la Real Academia de Historia (Quirosa 2006: 6-7 y 12). El motivo era el descubrimiento de un pecio romano mientras se construía un dique en el Arsenal de Cartagena. Obviamente esta medida no era de general cumplimento, sino que únicamente afectaba a la Armada.

En el inicio mismo del siglo xIx la Novísima Recopilación recogió dos disposiciones ${ }^{6}$ en las que por primera vez se definió jurídicamente al monumento, equiparándolo — como era propio del momento- a lo que hoy serían los hallazgos arqueológicos. Por primera vez existe una normativa de aplicación general que determina unas obligaciones en relación con los mismos. Descubridores, poseedores y Justicias —según el caso- tenían la obligación de dar "parte y noticia circunstanciada de todo" a la Real Academia de la Historia. ${ }^{7}$ Lo malo es que en ninguna parte quedaba claro qué sucedía en caso de no hacerlo.

Destacables son las creaciones de los Académicos Correspondientes de la Real Academia de la Historia en 1770 y de su Sala de Antigüedades y Diplomáti$\mathrm{ca}^{8}$ en 1792. Los primeros llegaron a conformar una red nacional de inspección e información sobre los descubrimientos y agresiones patrimoniales en su ámbito geográfico. Su labor contribuyó notablemente al "salvamento" de no pocos vestigios arqueológicos, tanto muebles como inmuebles (Tortosa y Mora 1996 y Almagro-Gorbea y Maier 2003). Cabe apuntar, sin embargo, que habida cuenta de su condición de eruditos de la época muchos de ellos eran también coleccionistas. En consecuencia, simultaneaban sus funciones académicas con el acrecentamiento de sus colecciones que, posteriormente, vendían o cedían a las instituciones.

La desamortización de Mendizábal de 1836 comportó unos resultados inesperadamente desastrosos para el Patrimonio Histórico. Para enmendarlo se acabaron creando en 1844 las denominadas Comisiones de Monumentos que, según Joan Ganau, deben ser consideradas como la "piedra fundacional de la política de conservación de monumentos en España" (Ganau 1998: 14), iniciándose así mismo las declaraciones de monumentos nacionales. ${ }^{9}$ A pesar de todos

6. Instrucción de 26 de marzo de 1802 y la Real Cédula de 6 de julio de 1803, incluidas en la Ley III, Título XX del Libro VIII. En relación con la segunda en 1818 se expidió Instrucción sobre Segóbriga y en 1827 una Real Orden sobre Itálica, para evitar el grave deterioro y expolio de dichos yacimientos.

7. Segundo punto de la Instrucción de 26 de marzo de 1802 .

8. Hacia la segunda mitad del siglo XIX pasó a denominarse Comisión de Antigüedades, Geografía, Cronología y Paleografía y a partir de 1991, Comisión de Antigüedades y Estudios Clásicos (Maier 2003: 27).

9. El primer monumento nacional en declararse fue la catedral de León en 1844. Los primeros yacimientos arqueológicos, propiamente dichos, fueron Numancia (1882) e Itálica (1912). Aunque pueda ser discutible, no he referido la declaración en 1896 del teatro romano de Sagunto como yacimiento arqueológico al haberse hecho como elemento aislado, sin considerar el conjunto de la antigua Arse - Saguntum de la que formó parte indivisible. 
estos esfuerzos, tal y como señalan Jordi Campillo y Susana Romero, el hecho de legislar a golpe de decreto y de real orden originó un laberinto legal, acumulándose tantas disposiciones que en definitiva no hacían más que dificultar la aplicación efectiva de las normativas vigentes (Campillo y Romero 2016: 9). Salvo los frustrados intentos de 1873 y 1883 no será hasta 1911 que se promulgue una Ley propiamente dicha (Alay 2015: 33-35).

A partir de la segunda mitad del siglo XIX, se constatan solicitudes de permisos para realizar excavaciones en terrenos propios y ajenos. Las solicitudes proceden de burgueses e intelectuales con sobrados recursos económicos. Estos permisos se concedían por Real Orden o a través del Ministerio de Fomento (Tortosa y Mora 1996: 203). Sin generalizar, puesto que siempre habrá excepciones, pretendían con ello regularizar la propiedad de los "tesoros" que se hallaren, conforme estipula la legislación civil, para la formación y acrecentamiento de sus propias colecciones. Por tanto estas "excavaciones" se limitaban a la recuperación de objetos y en modo alguno podemos considerarlas intervenciones arqueológicas.

En este período de confusa y generalmente ineficaz protección legislativa del patrimonio histórico se enmarca el protoarqueofurtivismo. A modo ilustrativo reseñaremos algunos casos.

Durante el siglo XIX y principios del xx, el saqueo de la antigua ciudad de Empúries (L'Escala, Girona) adquirió unas dimensiones más que notables. Las colecciones "privadas" de objetos arqueológicos aumentaron exponencialmente y, en paralelo, las excavaciones "privadas" para proveerlas (Alay 2015: 36-56). Entre ellas singularizamos dos casos muy significativos: el del emblema musivario sobre el sacrificio de Ifigenia y el del busto de bronce conocido como la Dama Flavia.

Fruto de una asociación de algunos ilustrados vecinos de L'Escala con el fin de "buscar preciosidades y conservar antigüedades o restos de edificios que la casualidad ofreciere o quizás se hallaren" se descubrió -antes de finalizar el año 1848 o a principios de 1849- el mosaico con el emblema que representa el sacrificio de Ifigenia. En el contexto de la época, aunque me reitere, no es descartable que el objeto real de dicha asociación fuera el enriquecimiento de las colecciones de sus socios, que para ellos constituían una medida efectiva de protección del patrimonio arqueológico.

Sin embargo, la imposibilidad de repartirse la pieza y la expectativa de obtener un buen precio - con el que podrían seguir financiando sus actividades y colecciones-, motivaron probablemente la decisión de venderlo. En 1851 consta ya construida encima del mosaico una sólida y cerrada caseta de obra, que se abría para interesados y unos posibles compradores que jamás llegaron.

$\mathrm{Su}$ recuperación por parte de las instituciones públicas fue un proceso largo sobre el que ya se ha escrito (Barral 1989; Buscató y Pons 2002) de adquisiciones parciales y subastas judiciales. El mosaico permaneció encerrado en su caseta hasta 1937, cuando desde la Generalitat se ordenó arrancar el emblema y transportarlo a Barcelona para protegerlo del pe- ligro que implicaba el conflicto armado. No regresó definitivamente a Empúries hasta el año 1956.

Más modesta fue la asociación que conllevó el descubrimiento de la renombrada Dama Flavia. Tres albañiles en paro de L'Escala la descubrieron en 1892. Despertó gran expectación, llegándose a publicar incluso que en realidad era de oro. Tampoco se produjeron las esperadas ofertas y para incentivarlas se llevó hasta Barcelona, donde se expuso públicamente en una chocolatería. Finalmente la adquirió Ferrer y Carreras, pasando posteriormente a la colección Güell, quien en 1936 la cedió al Museo Arqueológico de Barcelona (Alay 2015: 41-44). ${ }^{10}$

En grupo o no, muchas personas se dedicaron tenazmente, con más o menos fortuna, al expolio en Empúries, afectando especialmente a las numerosas necrópolis de su entorno inmediato. En su diario, Emili Gandia -excavador de campo en las excavaciones oficiales iniciadas en 1908- hace constar que le ofrecieron la posibilidad de poder vender los objetos en las mismas ruinas (Alay 2015: 47). La cantidad de materiales dispersos en colecciones y museos es desconocida pero no exageraríamos si los cuantificáramos por millares. La historia de todas estas piezas no puede darse por finalizada. Recientemente, en 2016, una casa de subastas madrileña vendió un alabastrón fruto de dichas actividades. Su triste historia y recorrido fue objeto de un artículo por parte de un renombrado arqueólogo (Almagro-Gorbea 2017) ${ }^{11}$ y poco más. Tras su fugaz reaparición pública, regresó al coleccionismo privado.

Los hallazgos casuales siempre se han producido y siguen produciéndose. Ahora bien, analizando las circunstancias de los descubrimientos y, especialmente, lo ocurrido inmediatamente después, se advierte que prácticamente nunca son todo lo casuales que cabría esperar y mucho menos altruistas.

El 25 de agosto de 1858 se halló casualmente el Tesoro visigodo de Guarrazar (Guadamur, Toledo). Advirtiendo sus descubridores el valor material de lo encontrado (oro y piedras preciosas) no acudieron de inmediato a las autoridades, sino que volvieron por la noche para proceder a la extracción de cuantos objetos pudieron. Posteriormente lo vendieron a distintos plateros toledanos. Al mismo tiempo, un vecino observó dichas correrías nocturnas y se puso a la labor, descubriendo un segundo lote del tesoro.

Todas estas personas no realizaron una única venta sino que durante años guardaron piezas en su casa, desprendiéndose paulatinamente de las mismas según las ofertas. Las peripecias y dispersión de este

10. El caso de la Dama Flavia puede seguirse en los boletines de la Asociación Artístico-Arqueológica Barcelonesa publicados en 1893. Especialmente núms. 1 (págs. 356-357), 2 (pág. 375) y 4 (pág. 420).

11. El alabastrón que nos ocupa es una cerámica ática de figuras negras atribuida al denominado pintor de Empúries (v a. C.). Se publicó por primera vez en 1908, constando como perteneciente a la Colección Montaner de Barcelona. Según averiguaciones del autor del reseñado artículo, en fecha desconocida - probablemente finalizada la guerra civil— pasó a la Colección Bofill hasta que en 2005 se vendió a la Galería F. Cervera-Arqueología de Barcelona. Este mismo año fue adquirido por un desconocido coleccionista particular de Zaragoza, quien lo vendió a la casa de subastas madrileña Jesús Vico, S. A. 
extraordinario tesoro ya han sido detalladamente expuestas e incluso noveladas (Balmaseda 1995a, 1995b y 1996)..$^{12}$

Por nuestra parte, interesa destacar que el "hallazgo casual" se reduce al momento del descubrimiento. A partir de ahí, todas las remociones realizadas para su extracción - tanto en el lugar como zonas inmediatas - son actividades que hoy día calificaríamos de arqueofurtivas.

Este mismo patrón conductual básico (descubrimiento / extracción-remoción en una o varias etapas / venta) se reproduce en bastantes de los tesoros que nos constan como hallados de forma casual, más allá incluso de la etapa protoarqueofurtiva: Aliseda (Cáceres) en 1920 (Rodríguez Díaz et al. 2014); Berzocana (Cáceres) en 1961 (Rodríguez Díaz et al. 2015); Villena (Alicante) en 1963 (Soler 1982),...

El expolio de los santuarios ibéricos se inició en la etapa prearqueofurtiva y ha seguido produciéndose hasta nuestros días. La extraordinaria dispersión de los exvotos —una auténtica diáspora-, tanto en España como fuera de ella, tanto en el ámbito público como en el privado, es prueba irrefutable. Solo un par de muestras.

La denominación de Cerro de los Santos (Montealegre del Castillo, Albacete) se usaba ya en el siglo XIV (Sánchez 2002: 61). Resulta evidente que desde hace siglos, se conocía la existencia de aquellos "santos" de piedra que se encontraban y, muy probablemente, se extrajeran del sitio. No fue, sin embargo, hasta las primeras décadas del siglo XIX —especialmente desde la tala masiva del bosque que cubría el cerro en 1830- que se advirtió su interés arqueológico. Las rebuscas incontroladas no se hicieron esperar.

Las primeras intervenciones autorizadas, por el propietario de la finca, se llevaron a cabo en 1870 por Vicente Juan Amat, conocido como el relojero de Yecla. Este primer y único permiso "legal" que tuvo le duró pocos días pero resultó muy provechoso. Según parece consiguió reunir hasta "dos o tres carros de estatuas y pedazos" (Sánchez 2002: 62). Después se dedicó a adquirir los objetos en manos de los vecinos de la zona, además de remover en otros yacimientos de la comarca. Aún así, el arsenal obtenido no satisfacía las demandas por lo que se dedicó a las falsificaciones de piezas por las que se le conoce (Montes 1993: 21-31). Caso similar es el de Francisco Serrano Cutillas y Bernardo Marín Díaz, el Corro y el Rosao, de Totana (Murcia), que por la

12. En la actualidad las piezas conocidas del Tesoro de Guarrazar (vII d. C.) se encuentran distribuidas entre el Museo Arqueológico Nacional, el Palacio Real de Madrid y el Museo Cluny de París. Se cree que la mayoría de las piezas descubiertas (coronas, cruces, cálices...), que probablemente duplicaban en número a las que se conservan, fueron fundidas por los plateros toledanos. Sin embargo, teniendo en cuenta que entre las desaparecidas se encuentran algunas de las más valiosas (se ha calculado que se hallaron unas veintitrés coronas votivas, de las que únicamente se conservan diez) y los robos, todavía sin resolver, de 1921 (entre otras destacadas piezas se llevaron la corona la Suintila) y 1936, no podemos descartar que alguna se encuentre en colecciones privadas. En 2018 y 2019 se han publicado dos novelas históricas sobre el caso (El último tesoro visigodo de José Calvo Poyato y Guarrazar, el Tesoro escondido de Pedro Antonio Alonso Revenga). misma época se dedicaron a la falsificación masiva a partir de los hallazgos del yacimiento argárico de La Bastida (Montes 1993: 106-127). En su caso, sin embargo, no he localizado evidencias de actividad arqueofurtiva, limitándose al parecer a la falsificación.

A finales del siglo xIx y principios del xx, salieron muchos exvotos de bronce del santuario ibérico Castellar de Santisteban (Jaén), ubicado en las cuevas de los Altos del Sotillo. El médico de Villacarrillo, Tomás Román Pulido, promovió las excavaciones para su colección y las de su entorno, aunque deba reconocerse que su turbia actividad ${ }^{13}$ contribuyó al posterior conocimiento científico del yacimiento. Entre 1895 y 1912 se constatan ventas intermediadas por este erudito, que al tiempo de realizar sus propias intervenciones mantenía relaciones de confianza con personajes como Juanico, a quien se llegó a calificar de "Rey de los Rebuscadores" (Bellón 2013: 61-62).

Habida cuenta del éxito de dichas actividades, algunos vecinos de Castellar llegaron a constituir una sociedad cuya finalidad era "explotar las riquezas arqueológicas que existían en el entorno inmediato de las cuevas" (Bellón 2013: 64). Por fortuna, duró apenas tres meses —entre 1912 y 1913 - pero aún así extrajeron más de mil objetos que posteriormente vendieron por unas 900 pesetas. Prácticamente todos los "lotes" fueron adquiridos por Juan Cabré Aguiló, gracias a la mediación de Tomás Román. ${ }^{14}$

En el estudio sobre la colección de Manuel Gómez Moreno, actualmente en la Fundación Rodríguez-Acosta (Granada) (Rueda 2012), se pudo verificar este método de oferta mediante "lotes". Conforme se puede verificar en los archivos fotográficos, en un primer tipo de lote se mostraban las piezas, sin ningún tratamiento de conservación, rudimentariamente dispuestas y atadas con cordeles a cartones. Cada cartón tenía de cuatro a quince piezas, mayoritariamente exvotos de bronce, pero también podía haber otros pequeños objetos como fíbulas. El segundo tipo de lote tenía una presentación mucho más cuidada. Las piezas aparecen cosidas sobre una tela, aparentemente son de mayor calidad y han recibido un tratamiento de limpieza y conservación. Corresponden a una segunda fase en la que intervenían coleccionistas o anticuarios que los habrían adquirido a los expoliadores (Bellón 2012: 69-71).

Generalmente el contenido de cada lote se vendía a un mismo comprador, pero con el tiempo han terminado en distintas ubicaciones. Gracias a estudios como el reseñado pueden identificarse piezas y, ocasionalmente, referencias sobre sus procedencias, vendedores, precio,... (Bellón 2012: 69). Lamentablemente el contexto se ha perdido.

13. Conforme explica Juan Pedro Bellón (Bellón 2016: 67, Nota 7), citando una obra anterior, en 1925 Tomás Román "trató de vender varios exvotos de bronce, procedentes de Castellar, en Oviedo. Decomisados por la policía, aludió que procedían de sus excavaciones autorizadas por la Junta Superior de Excavaciones y Antigüedades en Peal de Becerro".

14. Gran parte de esta colección la vendió a su vez al Museo Arqueológico de Barcelona, quedándose una parte que hoy se encuentra en el Museo Juan Cabré (San Antonio de Calaceite, Teruel). 
Ignacio Calvo, que junto con Juan Cabré había excavado en el Collado de los Jardines de Despeñaperros (Santa Elena, Jaén), intentó hacerlo en Castellar, encontrándose con la fuerte oposición de los vecinos. Exigían la mitad de lo que se encontrara. La cuestión se resolvió declarándose los terrenos de Utilidad Pública en 1915. De todos modos las actividades arqueofurtivas no cesaron. En 2001 se desarticuló en el marco de la Operación Sotillo -llevada a cabo por la Guardia Civil- a un grupo de personas que seguían expoliando el yacimiento (entre otras piezas se les encontraron 65 exvotos procedentes del santuario) (Alay 2015: 151). También se identificaron exvotos de Castellar en la colección de Ricardo Marsal (Ruiz y Rueda 2014) ${ }^{15}$ y en la Operación Reina - del Cuerpo Nacional de Policía-, publicitada en 2019, se intervinieron piezas procedentes de la Cueva de los Muñecos. ${ }^{16}$

En estas primeras etapas del arqueofurtivismo no disponemos de datos que permitan identificar actividades subacuáticas orientadas a la recuperación "clandestina" de materiales arqueológicos. En todo caso, se han documentado - ya desde los urinatores romanos- operaciones de salvamento de las cargas de los pecios. No podemos dejar de referenciar, sin embargo, los trabajos llevados a cabo por Romualdo Alfarás en Cala Cativa (El Port de la Selva, Girona), en 1894. Se consideran las primeras intervenciones arqueológicas subacuáticas de Catalunya - y probablemente de España-. Se extrajeron sesenta y dos ánforas del fondo marino, para lo que se contrataron a tres expertos coraleros de la zona. Los resultados se publicaron con el ilustrativo título de "Pesca de ánforas". Los hallazgos terminaron subastándose (Alfarás 1894 y Raurich 1994). ${ }^{17}$

\section{El arqueofurtivismo}

Como he indicado en publicaciones anteriores (Alay 2015: 497-499; 2016: 35-36 y 2018: 91-92), esta etapa propiamente arqueofurtiva (a partir de 1911) puede periodificarse. ${ }^{18}$ Hasta el momento la configuración de estos períodos no ha sido objeto de estudio pormenorizado, estando abierta a futuras investigaciones. Sin embargo, según lo verificado y los hechos especialmente significativos en relación con el arqueofurtivismo, propuse una diferenciación inicial de seis períodos. Partí de datos verificados en

15. Operación Tambora de la Guardia Civil, publicitada en 2002 (Alay 2015: 155-157).

16. Nota de Prensa del Ministerio del Interior de 15 de octubre de 2019.

17. Veinte de estas ánforas fueron a parar al entonces Museo Arqueológico de Barcelona. No se conoce ningún documento sobre la participación de Romualdo Alfarás en la subasta, considerándose que sus actividades nunca tuvieron una finalidad mercantilista. El yacimiento fue expoliado en la década de los sesenta por un grupo de submarinistas belgas procedentes de Port-Vendres (Francia). Actualmente se le conoce como Cala Cativa I, realizándose diversas intervenciones arqueológicas a partir de 2011 que han revelado una pequeña embarcación de época ibérica con un cargamento de ánforas tipo Pascual 1 (Vivar 2012: 21-24).

18. Sin duda también las anteriores (prearqueofurtivismo y protoarqueofurtivismo). Requiere un estudio todavía pendiente.
Catalunya pero considero que el esquema resultante, matizándolo, es perfectamente extrapolable a todo el territorio estatal.

Teniendo en cuenta lo dicho, presento esta periodificación con las siguientes modificaciones en relación a lo publicado con anterioridad:

- En función de la trascendencia que supuso la introducción del aparato detector de metales, he dividido el segundo período.

- Se adaptan las cronologías del tercer y cuarto períodos, ajustándolas a hechos de carácter estatal (Constitución de 1978 y Código Penal de 1995).

\section{Período 1911 - 1938: las leyes de 1911 y 1933}

La "Ley de 7 de julio de 1911 estableciendo normas a que han de someterse las excavaciones artísticas y científicas y la conservación de las ruinas y antigüedades" 19 marca el inicio de esta nueva etapa. En su artículo 1 define excavación arqueológica y en el 7 se obliga a disponer de previa autorización por parte del Estado. A partir de entonces podemos referirnos a actividades arqueofurtivas, propiamente dichas.

Esta Ley se mantuvo vigente durante más de setenta años, hasta la entrada en vigor de la actual Ley del Patrimonio Histórico Español de 1985. Aunque de hecho supuso un gran avance en la protección del patrimonio arqueológico, socialmente pasó muy inadvertida, considerándose más a efectos de trámites administrativos que no como instrumento eficaz de protección.

El relato de la visita de Josep Colominas —enviado por el Servicio de Excavaciones del Institut d'Estudis Catalans- a la necrópolis púnica del Puig dels Molins (Eivissa) en 1916, ejemplariza hasta qué extremos se ignoraba la Ley. Narra cómo le proporcionaron tres "guías" para visitar el laberíntico yacimiento. La exploración se realizó a la luz de un aparato de acetileno siguiendo una red de cuerdas para no perderse y volver a encontrar la salida. En vez de acceder a los hipogeos desde el exterior, se estableció comunicación interior entre unos y otros perforando las paredes divisorias. Lo que más desorientaba, según Colominas, era que las aberturas entre los distintos hipogeos tan pronto se abrían a nivel de suelo como del techo o a mitad de las cámaras.

Este método se implementó durante la ocupación musulmana de la isla, por lo que el saqueo ya se había iniciado siglos atrás, en la etapa prearqueofurtiva. Estos "guías" trabajaban tanto por cuenta de algún anticuario o coleccionista como por cuenta propia, vendiendo después sus hallazgos al primer viajero interesado (Colominas 1954).

El arqueólogo Miquel Tarradell escribió que este saqueo a gran escala de la necrópolis del Puig dels Molins duró más de un decenio, siendo la "época negra" entre 1910 y 1920 . Matiza que, desde el punto de vista oficial, únicamente eran saqueadores aquellos

19. Publicada en la Gaceta de 8 de julio de 1911. Su Reglamento de desarrollo se publicó en la Gaceta del 5 de marzo de 1912. 
que vaciaban tumbas sin el permiso que concedían los servicios del Estado. Desde el punto de vista científico, recalca que habían de considerarse como tales a todos los que actuaban sin ninguna preocupación técnica, tanto si lo hicieron por puro instinto comercial como siguiendo criterios coleccionistas, amontonando los hallazgos en su casa. Dejando a un lado las mejores o peores intenciones que les guiaron, su objetivo era recoger la mayor cantidad posible de objetos, sobre todo los más espectaculares, sin otra preocupación que no fuera el objeto en sí mismo (Tarradell y Font 1975: 20-21). ${ }^{20}$

Volviendo a Empúries, entre los años 1912 y 1915 — con la Ley en vigor - el carretero Pere Mitjavila saqueó totalmente una necrópolis romana de inhumación. Los materiales los vendió al Museo Arqueológico de Girona. Evidencia de que los museos seguían adquiriendo directamente a los arqueofurtivos (Alay 2015: 62).

La Ley de 1911 propicia la evolución en cuanto a gestión del patrimonio arqueológico. Muestra de ello es la organización en 1915 del Servei d'Investigacions Arqueològiques en Catalunya, amparado por la autonomía administrativa de la Mancomunitat.

Este período se cierra con la promulgación de la Ley de Patrimonio republicana en $1933^{21}$ y sus primeras consecuencias (Alay 2015: 70-74). Con pocas modificaciones sobre el texto, ${ }^{22}$ aunque con múltiples decretos que la irán reformando y completando haciendo complicadísima su coordinación, con el consiguiente perjuicio para la claridad y seguridad jurídica (Álvarez 1989: 47), estará vigente durante cincuenta y dos años hasta la promulgación de la actual en 1985.

En el ámbito que nos ocupa, sin embargo, mantiene vigente la legislación de 1911 y salvo algunas matizaciones en el articulado (Alay 2015: 70-71) no tuvo incidencia significativa.

De todos modos, a pesar de los casos que sin duda salpicaron toda la península, confieso no haber podido localizar antecedentes sobre ningún proceso sancionador por actividades arqueofurtivas.

20. Afirma Tarradell que uno de los que más se aprovechó de esta época negra fue Antonio Vives Escudero, entonces catedrático universitario de Numismática y miembro de la Academia de la Historia. Disponiendo de permiso oficial, organizó cuadrillas de obreros — que no fueron otros que los "guías" de Colominas - haciéndose con una gran colección ebusitana que después se vendió al Museo Arqueológico Nacional. Cuando en 1913 se iniciaron las excavaciones oficiales por parte del recientemente creado Museo d'Eivissa, Vives lo denunció reclamando la exclusividad de las excavaciones basándose en el permiso que seguía vigente. Los pleitos no se resolvieron hasta 1921, habiendo de indemnizar el Estado a Vives para poder autorizar nuevas excavaciones. Otros coleccionistas que también sacaron partido de esta época negra del Puig dels Molins, fueron José Costa Picarol y Santiago Rusiñol (Tarradell y Font 1975: 22-24).

21. Ley de 13 de mayo de 1933 sobre defensa, conservación y acrecentamiento del patrimonio histórico-artístico nacional publicada en la Gaceta de 25 de mayo de 1933. Su Reglamento de desarrollo se publicó en la Gaceta de 16 de abril de 1936.

22. La Ley se modificó en 1955 y el Reglamento en 1972.

\section{Período 1939 - 1967: las Comisarías y el Servicio Nacional de Excavaciones}

Tal y como he expresado en otras ocasiones, este segundo período se caracteriza por la creación y desarrollo de las denominadas Comisarías de Excavaciones y el Servicio Nacional de Excavaciones - a partir de 1955-, que favorecieron el mantenimiento de una extensa red de aficionados locales (DíazAndreu y Ramírez 2001). Entre tantos, los hubo que se excedieron en su cometido. No faltaron quienes al tiempo de colaborar activamente con los arqueólogos, mantenían sus propias intervenciones sin constancia oficial de las mismas (Alay 2018: 92).

Prácticamente al inicio de este período se inventó la escafandra autónoma (1943), con la que el expolio submarino se incrementó exponencialmente. En 1947 una Orden del Ministerio de Marina obligaba a comunicar cualquier hallazgo subacuático a la Comisaría General de Excavaciones Arqueológicas, atribuyendo a las Comandancias militares de Marina su vigilancia y control (Mederos y Escribano 2006). La Armada siguió desempeñando esta función hasta que de forma paulatina ha ido siendo sustituida por las administraciones y fuerzas de seguridad civiles —además de la Guardia Civil-. ${ }^{23}$

Durante este período apenas he podido localizar casos en los que se haya perseguido el arqueofurtivismo. No faltan alusiones en las publicaciones arqueológicas, resultando evidente que seguían produciéndose, aunque todo parece indicar que en general predominó la impunidad.

Un caso a modo de ejemplo, aunque ya me haya referido al mismo con anterioridad (Alay 2018: 92-93), es el de la necrópolis tumular leridana de Roques de Sant Formatge (Seròs). Consultando memorias de excavaciones, me encontré que en esta, realizada durante los años sesenta, se referían numerosas acciones arqueofurtivas.

Se calculaba que al menos una cuarta parte del yacimiento había sido recientemente expoliado. Denunciado el asunto, la Guardia Civil de Alcarràs consiguió identificar a un arqueofurtivo y recuperar un importante lote de materiales. A pesar de que el presunto siempre afirmó que todas las piezas procedían de una única tumba —la G-257-, y así se publicó en la memoria consultada, los arqueólogos nunca acabaron de creérselo. Comparándolo con los ajuares encontrados en los otros 112 túmulos del mismo sector, resultaba excesivo. Parecía más bien que las piezas que componían el lote procedían de varios ajuares, extraídos de distintas tumbas.

Hasta la fecha no ha sido posible encontrar ningún dato sobre el desenlace del caso (Pita y Díez-Coronel 1968 y Alay 2015: 78).

23. De todos modos en 2007, en razón del caso Odyssey —al que nos referiremos más adelante-, se aprobó el Plan del Patrimonio Arqueológico Subacuático en el que se contó con la participación de la Armada. 


\section{Período 1968 - 1977: introducción de los detectores de metales}

Es evidente, se diga lo que se diga, que el aparato detector de metales marcó un antes y un después en la historia del arqueofurtivismo español (Rodríguez Temiño 2003). De acuerdo con Jaime Almansa y Francisco Javier Matas, los aparatos detectores de metales probablemente se introdujeron en España entre los años 1967 y 1968, a través de las bases norteamericanas de Morón de la Frontera, Torrejón de Ardoz, Zaragoza y Rota (Almansa y Matas 2018: 39).

Las experiencias vividas o explicadas por sus compañeros durante la limpieza de minas después de la Segunda Guerra Mundial en Francia, Italia, Grecia..., propiciaron que algunos soldados americanos probaran suerte en España (Alay 2015: 263-264).

El arqueólogo Fernando Fernández Gómez recordaba que veía con desesperación cómo se paseaban impunes por nuestros campos, cuando estaban siendo arados, los militares americanos con los primeros detectores. Citaba el nombre de los sargentos Brown y Mc Shane, del cuerpo de bomberos de la base de Morón, así como de un personaje de quien se decía era el jefe de Seguridad de la base de Rota. Había quien aseguraba haberlos visto desplazarse a los yacimientos incluso en helicóptero. También se decía que hubo militares que regresaban a su tierra, directamente desde las bases y sin pasar por ninguna aduana, cargados con cajones de objetos (Fernández 1996: 292-293).

Además de probarlos hicieron negocio distribuyéndolos, sea directamente o a través de los trabajadores de las bases. Al parecer el principal foco de introducción fue la de Morón. El apodado "Barbero de La Lantejuela", peluquero de dicha base, fue posiblemente el primer concesionario de detectores de metales en España. Alquilaba los aparatos a desempleados y jornaleros. Cobraba quedándose con la mitad de lo que encontraban.

Por las mismas fechas, debe reseñarse al propietario del bar denominado El Denario de Écija, también peluquero y detectorista. Fue uno de los primeros lugares documentados en los que se negociaba con las piezas halladas (fundamentalmente monedas) (Rodríguez Temiño 1998: 29 y 2000: 36). ${ }^{24}$

Es muy posible que la expansión por toda la península fuera favorecida - como apuntan los citados autores Almansa y Matas (2018: 40) - por el éxito del programa Misión Rescate. Organizado por el Ministerio de Información y Turismo se produjo conjuntamente por RTVE y RNE, estrenándose en 1967 y emitiéndose hasta 1978. El objetivo era salvar obras de arte y vestigios arqueológicos. Para ello se convocaba a maestros de primaria y secundaria para que organizaran grupos de alumnos con los que se dedicaban a su búsqueda. Los mejores hallazgos tenían premio y reconocimiento social.

24. Agradezco las informaciones sobre El Barbero de La Lantejuela y el bar Denario, así como las relacionadas sobre Fuente Tójar y Cabra (Córdoba) — que referiré más adelante-, facilitadas por Ignacio Rodríguez Temiño.
Aunque no hay datos confirmados, existen indicios - habida cuenta del carácter de los hallazgos- de la probable utilización de aparatos detectores de metales por parte de algunos concursantes. De ahí que se apunte la posibilidad de que contribuyera en alguna medida a su difusión indiscriminada.

Desconozco si nunca ha llegado a realizarse un estudio sobre el impacto, tanto positivo como negativo, de este popular programa en el patrimonio histórico. Es muy probable que fuera un potente instrumento de concienciación y sensibilización social, pero no podemos descartar que al tiempo alentara otras "vocaciones" muy alejadas de su objetivo primigenio.

El expolio del patrimonio histórico, en general, se agrava de tal forma que en el artículo 46 de la Constitución de 1978 se obliga expresamente a que la ley penal sancione "los atentados contra este patrimonio".

\section{Período 1978 - 1984: impunidad}

Durante este período el arqueofurtivismo en España alcanzó su máxima intensidad, al menos que se haya podido documentar.

Si los años precedentes se caracterizaron por la introducción de los aparatos detectores de metales, la segunda mitad de los setenta y especialmente la primera de los ochenta destacaron por la proliferación de dichos aparatos, afectando incluso a yacimientos prehistóricos, a pesar de su inutilidad en los mismos.

Aparte de una muy escasa concienciación y sensibilización hacia el patrimonio histórico por parte de la mayoría de la población, había un gran desconocimiento sobre su continuado expolio. La economía durante estos primeros años de la transición no era precisamente boyante, constituyendo probablemente otro de los factores determinantes.

Concretamente, en Andalucía coincidió con la crisis del medio de vida de miles de jornaleros ante la anunciada reforma agraria. En un reportaje, publicado por El Periódico en 1981, se exponía la situación ejemplificando en el pueblo sevillano de Lantejuela, donde se decía que muchos de sus vecinos se dedicaban a explorar con detectores y, según explicaban, había familias que disponían de hasta tres aparatos..$^{25}$ En 1983 se publicó en el diario El País un reportaje similar, en el que se hacía referencia al denominado "romboide" conformado por Carmona, Écija, Estepa y Morón de la Frontera, donde el expolio arqueológico era más intenso. ${ }^{26}$

Ignacio Rodríguez Temiño, entonces arqueólogo municipal de Écija —en el corazón del triangulo negro del expolio (Rodríguez Temiño 2012: 1) ${ }^{27}$-, considera exagerado el contenido de los reseñados reportajes. Explica que es cierto que la expansión del uso de los detectores coincidió con la roturación profunda mediante subsoladores de muchos

25. Reportaje de Andre Misse, “Jornaleros andaluces sobreviven con la venta de monedas antiguas", publicado en El Periódico del 1 de mayo de 1981.

26. Reportaje de Alfredo Relaño, “Tesoros para jornaleros sin tajo", publicado en El País el 11 de septiembre de 1983.

27. "Triángulo negro" cuyos vértices eran Alcolea del Río, Osuna y Carmona (Rodríguez Temiño 2012: 1), viene a coincidir aproximadamente con el "romboide" citado. 
olivares, originando hallazgos arqueológicos a la vez que desempleo, fomentando ambas circunstancias un comercio relativamente rentable para quienes se iniciaban en el uso de los detectores. Pero también es cierto que ya entonces había subsidios agrícolas y las actividades arqueofurtivas no compensaban tanto como la construcción o el comercio. El mismo autor facilita el dato contrastado de una docena corta de arqueofurtivos activos en Écija a mediados de los años ochenta (Rodríguez Temiño 1998: 26 y 2012: 86-87), frente a los cientos que se presumían en los citados reportajes.

Cifras aparte, los primeros buscadores andaluces fueron esencialmente eruditos, pronto superados por quienes lo hacían por afán de lucro. Algunos de los más "entendidos" se hicieron intermediarios con los anticuarios, coleccionistas y museos, mejorando su nivel de vida. Lo que empezó como una necesidad se convirtió en medio de vida, extendiendo incluso su radio de acción a otras comunidades. Esta tendencia, aunque las razones, la intensidad y las maneras de hacer han ido cambiando, se ha mantenido hasta hoy día (Rodríguez Temiño 2012: 90).

No es posible extrapolar este comportamiento a todo el territorio. En el otro extremo, en Catalunya, a pesar de sufrir también el uso indiscriminado del detector, las motivaciones fueron muy distintas, No fue la necesidad lo que mayoritariamente incentivó a los detectoristas catalanes, ni los eruditos o aficionados, sino más bien el coleccionismo numismático y bélico. En este sentido, los frentes del Ebro y del Segre de la última contienda civil (1936-1939), así como sus entornos, fueron -y siguen siendo- los más "castigados". De todos modos, cabe decir que sobre este período más de una vez he afirmado que más del $90 \%$ de los yacimientos arqueológicos catalanes conocidos resultaron afectados en mayor o menor medida.

Desde el principio los detectoristas constituyeron asociaciones por todo el territorio nacional, destacando en número las andaluzas. Primero fueron asociaciones locales, después regionales, evolucionando hacia una federación estatal. ${ }^{28}$

Posiblemente en este período es cuando se empezó a popularizar el término "piteros", a razón del sonido que emitían los aparatos al detectar un "blanco" — conforme su terminología-. Ha llegado a tener tanto éxito que ahora habitualmente se utiliza para denominar a los arqueofurtivos. Es erróneo. Hay distintos tipos de arqueofurtivos y no todos utilizan un detector de metales para llevar a cabo su actividad expoliadora.

Ante la impunidad y la impotencia, muchos arqueólogos sembraron literalmente los yacimientos de objetos metálicos (clavos, limaduras, chapas...) para confundir las detecciones y hacerles desistir (Alay 2015: 268). Hubo quien, aprovechando oportunidades, llegó a inutilizar algún que otro aparato aplicándoles

28. Ignacio Rodríguez Temiño realizó una excelente "radiografía” de estas asociaciones en el apartado "De piteros a detectoaficionados” en su libro (Rodríguez Temiño 2012: 105111) sobre la que resultaría reiterativo insistir, remitiéndome a la misma. corriente continua (Rodríguez Temiño 2012: 1-2). Un caso extremo sucedió en un yacimiento de la provincia de Toledo, donde un arqueólogo rogó a un destacamento militar en maniobras que disparasen con sus fusiles ametralladores contra el yacimiento. Se pretendía que la gran cantidad de balas obligara a los detectoristas a abandonar su búsqueda, pero al parecer no tuvo mucho éxito. Los aparatos mejoraban y se iba implementando el uso del discriminador. ${ }^{29}$

También se empezaron a vallar los yacimientos pero tenía un alto coste y su efectividad era discutida. En zonas aisladas resultaban más un reclamo que una protección. Poner carteles, aunque no hubiera valla, también se intentó como medida disuasoria. Algunos arqueólogos, de acuerdo con el propietario, cerraban los accesos o ponían letreros del estilo "Prohibido el paso. Propiedad privada” (Alay y Clariana 2018: 116). En general los resultados no fueron satisfactorios.

Lamentablemente, algunos arqueólogos, después de no pocas denuncias sin ningún efecto, optaron por la connivencia con los arqueofurtivos que operaban en su área de estudio. Se facilitó permisividad a cambio de poder estudiar las piezas o acordar que no actuaran en determinados yacimientos. Lo peor es que estas actitudes se han mantenido en el tiempo.

Cabría analizar las motivaciones de tanta impunidad. Debe tenerse en cuenta que por aquel entonces la administración se excusaba en el laberinto legal de decretos, expectante de una nueva e imprescindible Ley, en la formación y estructuración de las autonomías así como en el traspaso de competencias.

A pesar de todo, debe destacarse la Orden de la Dirección General de Política Interior del Ministerio del Interior, emitida el 23 de abril de 1980 y dirigida a todos los gobernadores civiles, instando a la máxima colaboración de la Guardia Civil y demás agentes con las autoridades delegadas del Ministerio de Cultura para hacer "cumplir la legislación vigente y vigilen cuantas infracciones contra ellas se produzcan mediante el empleo de detectores metálicos aplicados a las excavaciones o remociones arqueológicas" (Alay 2015: 79).

Dicha Orden se emitió un año antes que la Recomendación 921 del Consejo de Europa sobre Detectores de Metales y Arqueología. En su apartado 14 ya se recomendaba entonces (año 1981) al Consejo de Ministros europeo que "considerase adoptar, como una cuestión de urgencia, recomendar a los gobiernos instituir un sistema de licencias o registro de usuarios de detectores de metales". En 1992, volvió a insistirse en la necesidad de adoptar esta medida en el Convenio europeo para la protección del patrimonio arqueológico, celebrado en La Valetta (Alay 2015: 265).

El hallazgo en 1982 de la primera lámina de plomo con epigrafía ibérica hallada en tierras leridanas, mientras su descubridor buscaba material bélico con

29. Reportaje de Pedro Corral, "Los arqueólogos alarmados ante la creciente acción de los saqueadores", publicado en el diario $A B C$ de 19 de febrero de 1989. Aunque cronológicamente este reportaje se corresponda al período posterior (1985-1994), me he permitido la licencia para ilustrar unas conductas que se repitieron en ambos períodos. 
un detector de metales, dio a conocer a un grupo de personas dedicadas a la detección metálica. En un artículo publicado en el diario La Mañana el 5 de agosto de 1983, el "jefe" de dicho grupo declaró que dedicaba un promedio de veinte horas semanales a la búsqueda fotografiándose con "sus piezas" e informando incluso sobre el lugar del que procedían. Manifestó que en Lleida había unas ocho o nueve personas que se dedicaban a buscar monedas, pero únicamente uno de ellos lo hacía para venderlas.

Se procedió a la incoación de expediente sancionador por parte de la Generalitat -el traspaso de competencias en materia de cultura se había producido en 1981-, saldándose en 1989 con la incautación de material arqueológico. Desde la administración se declaró que era la única sanción posible, ya que las leyes vigentes seguían sin establecer una sanción económica y las experiencias en vía penal eran frustrantes (Alay 2015: 80 y 2018: 93).

En julio de 1984 el Gobierno Civil de Cádiz publicó en el Boletín Oficial de la Provincia una Circular sobre "excavaciones clandestinas y buscadores desaprensivos con detectores de metales". ${ }^{30}$ Se realizó distribución a todas las autoridades implicadas, pero desconozco los efectos que realmente tuvo.

En septiembre de 1984 se publicó que la Guardia Civil de Fuente Tójar (Córdoba) había sorprendido a tres vecinos de Lantejuela (Sevilla) cuando provistos de detectores de metales buscaban "monedas y objetos antiguos" careciendo de autorización. Les incautaron "cuatro vasijas, una espada, una punta de lanza y dos monedas". ${ }^{31}$ Desconozco el desenlace.

En 1985, antes de la entrada en vigor de la Ley de patrimonio histórico, el alcalde de Cabra (Córdoba) dictó un bando en el que se recordaba la prohibición de toda remoción deliberada de terrenos con indicios de yacimiento arqueológico sin la debida autorización de la Junta de Andalucía. Además puntualizaba que "el uso de detectores de metales con propósito de encontrar piezas arqueológicas estaba prohibido y constituía delito". Por el contenido del bando se desprende que se habían producido actividades arqueofurtivas en su término "por parte de ciudadanos de otros municipios y de éste”, nada sorprendente habida cuenta de su ubicación muy cercana al referido triángulo negro. El delegado provincial de Cultura felicitó al alcalde "por la adopción de tan encomiable iniciativa". Probablemente no sea un caso aislado - esperemos- que ejemplariza los esfuerzos e iniciativas emprendidas desde la administración local ante la gravedad de la situación.

30. En la Circular se dice expresamente: "La creciente utilización de numerosos tipos de detectores de metales, algunos altamente sofisticados, ha popularizado las exploraciones y rebuscas que, aún encubiertas muchas veces bajo el aspecto de pasatiempo, han de considerarse como auténticas exploraciones arqueológicas en la mayor parte de los casos, por corresponder exactamente a la definición dada por la Ley de Excavaciones Arqueológicas de 7 de julio de 1911 (...)”. Publicada con el número 3.561 en el BOP de Cádiz. núm. 159 de 9 de julio de 1984.

31. Información publicada en el diario Córdoba del 19 de septiembre de 1984.
Destacable en este periodo es la celebración del Coloquio sobre la protección del Patrimonio Arqueológico celebrado el 3 de marzo de 1984 en Barcelona y organizado por la Societat Catalana d'Arqueologia (SCA). Básicamente se debatió sobre la necesidad de redefinir profesionalmente la figura del arqueólogo como encargado y al mismo tiempo responsable del patrimonio arqueológico en toda su amplitud, en un momento en el que ya circulaban borradores de la futura Ley de patrimonio histórico. ${ }^{32}$

Uno de los aspectos tratados fue el expolio del patrimonio subacuático y los detectores de metales. En un muestreo efectuado por las instituciones arqueológicas catalanas se puso de manifiesto que el $80 \%$ de los yacimientos arqueológicos submarinos que entonces se conocían en Catalunya estaban, desde el punto de vista arqueológico, prácticamente destruidos a consecuencia de la expoliación y que de todas las piezas arqueológicas extraídas, menos del $5 \%$ estaban en colecciones públicas y más del $95 \%$ en colecciones privadas, la mayor parte en el extranjero. ${ }^{33}$ En relación con los detectores de metales, se propuso en la ponencia que provisionalmente los ayuntamientos acordaran su prohibición, ante la demora en la elaboración de un Decreto regulador promovido por el Departamento de Cultura de la Generalitat -que nunca llegó a publicarse- (Adell et al. 1984).

\section{Período 1985 - 1994: la Ley estatal de 1985 y desarrollo autonómico}

Finalmente, en 1985 se promulgó y publicó la vigente Ley 16/1985, de 25 de junio, del Patrimonio Histórico Español y un año más tarde el Real Decreto 111/1986, de 10 de enero, que la desarrolló parcialmente. Entre las dos disposiciones prácticamente se derogó toda la normativa anterior sobre la materia. ${ }^{34}$

Si la anterior Ley de 1933 fue modelo para la italiana de 1939, la actual de 1985 debe su contenido ideológico a la doctrina italiana. Se fundamenta en la denominada teoría de los bienes culturales - desarrollada por el profesor Massimo Severo Giannini en la primera mitad de los años setenta-, diferenciando en un mismo soporte físico sus diferentes utilidades pudiendo ser cada una de ellas objeto de una diferenciada tutela jurídica. De este modo, un mismo soporte físico puede tener en función de sus diferentes utilidades, diferentes titulares.

32. Artículos periodísticos de Rosa María Piñol, "Los arqueólogos se reúnen para reivindicar su papel en la protección del patrimonio", publicado en el diario La Vanguardia del 3 de marzo de 1984 y de J. A., "Los arqueólogos reclaman su papel en la defensa del patrimonio", publicado en el diario El País de 12 de marzo de 1984. Lamentablemente la ponencia sobre la que se debatió no llegó a publicarse.

33. Reportaje de Mitzi Kotnik, "Arqueòlegs i arquitectes han de restaurar en col-laboració", publicado en el diario El Món de 30 de marzo de 1984.

34. Sobre la génesis e interpretación de la Ley de 1985 debe consultarse la monografía de José Luis Álvarez (Álvarez 1989), ponente de la Ley en el Congreso de los Diputados. Sobre su contenido se han publicado diversas tesis doctorales, destacando las de Concepción Barrero (Barrero 1990), María del Rosario Alonso (Alonso 1991) y especialmente la de Juan Manuel Alegre (Alegre 1994). 
Para Giannini los denominados bienes culturales tienen un componente diferenciado de disfrute colectivo, correspondiendo la titularidad del mismo a la administración competente. Cuando en un bien cultural se produce una interferencia de este derecho de disfrute colectivo con el derecho de propiedad, la doctrina ha considerado que la regla general es el mantenimiento de ambos mientras sean compatibles y en caso negativo prevalecerá el derecho de disfrute colectivo.

Esta doble titularidad teórica permitió resolver la problemática surgida desde el inicio de la regulación del Patrimonio Histórico, dando fuerza a la administración en cuanto a los hallazgos arqueológicos que la nueva ley consideró de dominio público (artículo 44).

En la Ley 16/1985 se facilitan nuevos conceptos de expolio (artículo 4), excavación y prospección arqueológicas así como de los hallazgos casuales (artículo 41), superando a los que únicamente se perfilaban en la derogada Ley de 1911 y su Reglamento. También se prevé un régimen sancionador (artículos 75 a 79).

En la Disposición adicional primera del Reglamento se regulan las intervenciones policiales. En este sentido, se crean o reorganizan unidades específicas.

El Cuerpo Nacional de Policía, a partir del Grupo de Robos —creado en 1977 ante la proliferación del expolio que se producía en el patrimonio eclesiástico rural- constituyó la Brigada de Patrimonio Histórico, dependiente desde 2005 de la Unidad Central de Delincuencia Especializada y Violenta (UDEV), cuyo Grupo Operativo I se encarga de investigar el expolio arqueológico.

Por su parte, la Guardia Civil también a finales de la década de los años setenta y por los mismos motivos centralizó las investigaciones sobre el patrimonio histórico en la Unidad de Servicios Especiales, hasta que en 1987 se estructuró el actual Grupo de Patrimonio Histórico de la Unidad Central Operativa (UCO). Finalmente en 1988 se creó el Servicio de Protección de de la Naturaleza (SEPRONA), siendo muy destacada su labor contra las actividades arqueofurtivas.

La Ley 16/1985 fue objeto de diversos recursos de inconstitucionalidad por parte de algunas comunidades autónomas, ${ }^{35}$ sobre los que el Tribunal Constitucional dictó sentencia en 1991. Por nuestro interés destacar los recursos al artículo 4 relativo al expolio, motivados en el fondo por la competencia exclusiva sobre el mismo del Estado de acuerdo con lo establecido en el artículo 149.1.28 de la Constitución. La sentencia acabó desestimando su inconstitucionalidad aunque admitiendo la complementariedad de competencias en la lucha contra el expolio. Ello obligó a modificar el Reglamento de la Ley 16/85, añadiendo el artículo 57 bis en el que se regula la intervención de las distintas administraciones en los casos de expolio (Alay 2000: 49-53).

Este nuevo marco legal propició la promulgación de las correspondientes leyes autonómicas en la mayoría de las comunidades y, en consecuencia, la incoación de los primeros expedientes sancionadores por arqueofurtivismo.

35. Recurrieron la Generalitat y el Parlamento de Catalunya, la Xunta de Galicia y el Gobierno Vasco.
Las nuevas regulaciones condicionaban a menudo las autorizaciones a la acreditación, por parte de los directores de intervenciones arqueológicas, de unos conocimientos y experiencia. En no pocas ocasiones implicó descartar a una serie de aficionados que seguían interviniendo por todo el territorio. Algunos mostraron su rechazo a la nueva situación e incluso la ignoraron. Representativos son los casos del Turó del Vent (Llinars del Vallès, Barcelona) y Turó de Sant Feliuet de Savassona (Tavèrnoles, Barcelona), ocurridos en 1985 y 1993. En ambos casos se sorprendió en plena actuación y denunció a personas consideradas por su entorno como eruditos y benefactores de la cultura local. Aunque se consiguió que desistieran de sus actividades, las presiones vecinales en su favor impidieron sancionarles (Alay 2018: 94).

Durante los años 1986 y 1987 se produjeron en Catalunya una serie de hechos que aisladamente, a pesar de su importancia, probablemente habrían pasado desapercibidos, pero al coincidir adquirieron una inesperada fuerza y motivaron una inflexión, incluso a nivel estatal, en lo que hasta entonces era una problemática en expansión.

El mes de mayo de 1986 se sorprendió a dos arqueofurtivos en plena actividad en la necrópolis ibérica de Dos Pins (Cabrera de Mar, Barcelona). Este hecho, sobre cuyas circunstancias he tratado anteriormente y no cabe reiterar (Alay 1991; 2015: 435-445, así como en Alay y Clariana 2018: 118-123), tuvo importantes consecuencias.

La sanción impuesta fue la más elevada hasta entonces. En total 500.000 pesetas $(3.005,06 €)$. La reconocida reincidencia de uno de los arqueofurtivos le costó 400.000 pesetas $(2.404,05 €)$.

En septiembre de 1987 la revista Interviú publicó la fotografía de estos dos arqueofurtivos en plena actividad. ${ }^{36}$ La entonces popularidad y gran tirada a nivel estatal de este semanario repercutió en un ambiente hasta entonces muy desconocido y apenas perturbado. Dos meses antes la misma revista había publicado un primer reportaje sobre el expolio de los yacimientos arqueológicos subacuáticos.

La publicación del segundo reportaje coincidió con una acción policial que en aquellos momentos era muy inusual: la Policía Nacional detuvo el 19 de septiembre de 1987 a tres personas relacionadas con el expolio de yacimientos arqueológicos y, concretamente, a partir de las actividades realizadas en la necrópolis de Dos Pins. Este operativo, que tuvo cierta difusión mediática, ${ }^{37}$ puede calificarse de pionero en la materia que nos ocupa.

36. La imagen de los arqueofurtivos in flagranti crimine se publicó en el reportaje de Pepe Rodríguez, "Piratas del Arte", publicado en el número 590 (septiembre de 1987) de la revista Interviú. El 3 de junio de 1989 se publicó en el diario El País y posteriormente en el semanario El Temps ("Lladres molt exquisits", núm. 601, diciembre de 1995) y en el diario El Punt Avui ("Espoliadors del Patrimoni", febrero de 2013).

37. La noticia se publicó el 26 de septiembre de 1986. El diario Avui, tituló "Nou cop als espoliadors professionals de peces arqueològiques". El Periódico, "La policía detiene a dos saqueadores de restos arqueológicos"; el Diari de Barcelona, "Detinguts per destrossar jaciments arqueològics del període ibèric"; El Punt, "Detinguts a Mataró acusats d'espoliar diversos jaciments"; La Vanguardia, "Detienen a tres personas por la expoliación de yacimientos arqueológicos": El País, "Detenidos tres traficantes de valiosas piezas arqueológicas". 
En los registros se incautaron de unas cincuenta piezas procedentes - se dijo- de Caldes de Montbui (Barcelona), Cabrera de Mar (Barcelona), zonas de Lleida e incluso de Jaén. También se incautaron dos walkie-talkie con los se comunicaban "cuando realizaban alguna expoliación complicada".

Para sorpresa de los agentes, en el momento de ser detenidos les mostraron sus carnets de una asociación de detectoristas, método que - según explicaron después- ya lo habían utilizado con éxito en más de una ocasión. Puestos a disposición judicial y después de pasar tres días en la cárcel Modelo de Barcelona, fueron puestos en libertad sin fianza. Este hecho no fue bien visto por los responsables policiales del operativo: "si estas personas son liberadas con tanta facilidad es muy probable que actos de las mismas características se den con mayor frecuencia", añadiendo que "sigan o no este tipo de robos dependerá en gran medida de la resolución que se haga de este caso".

En el juicio, celebrado el 30 de abril de 1998, se aclararon las circunstancias y el rol de los tres detenidos: el primero era el presunto autor material de las actividades arqueofurtivas; el segundo era el supuesto intermediario, con una tienda en Mataró donde se descubrieron las piezas incautadas, y el tercero era el coleccionista que presuntamente las adquiría. Los tres fueron absueltos por prescripción del delito de hurto - para el primer acusado-, falta de pruebas y porque no se pudo determinar la procedencia exacta de los materiales incautados, que podían haber sido adquiridos en el mercado. ${ }^{38}$

Otra consecuencia del caso de Dos Pins fue la de acelerar la creación de la Brigada de Patrimonio Histórico del Cuerpo de Mossos d'Esquadra, en septiembre de 1986 (Rabadán 2007: 394 y 2008: 103). Inicialmente con solo dos efectivos, este grupo policial contribuyó decisivamente a la reducción del arqueofurtivismo en Catalunya. Constituyeron el embrión de la actual Unidad Central de Patrimonio Histórico.

Así mismo, motivados por los hechos de Dos Pins y anticipándonos a una probable reorganización de quienes se dedicaban al expolio arqueológico, el mes de junio de 1986 se presentó sin dilación un informe sobre el tráfico de material arqueológico procedente de actividades arqueofurtivas que se llevaba a cabo en el mercadillo dominical de la plaza Reial de Barcelona. Hacía tres meses que, por parte de la Comisión de Patrimonio de la SCA, ${ }^{39}$ manteníamos un seguimiento en determinadas paradas (Alay 1990: 7; 1991: 132-134 y 2013: 61). A raíz del contenido de este informe, un año más tarde —mayo de 1987-,

38. Artículo de Teresa Márquez, "Jutgen tres homes acusats de robar i vendre peces d'un jaciment arqueològic a Cabrera", publicado en el diario El Punt del 1 de mayo de 1998.

39. Entre 1986 y 1995 la Comisión de Patrimonio de la SCA registró 68 informes de los que 20 se referían directa o indirectamente a actividades arqueofurtivas. Además de los casos de Dos Pins y Plaça Reial, destacó el de Tivissa. En septiembre de 1986 se sorprendió a unos arqueofurtivos con detectores de metales en el yacimiento ibérico del Castellet de Banyoles (Tivissa, Tarrgona). Los datos aportados en el Informe de la Comisión de Patrimonio SCA y su ratificación por parte de los autores del mismo ante el Departamento de Cultura, permitieron identificar y sancionar a uno de los arqueofurtivos con una multa de 60.000, pesetas $(360,61 €$ ) (Alay 2015: 85). la Brigada de Patrimonio Histórico irrumpió en una numismática barcelonesa, en la que se incautaron " 30 bolsas con material arqueológico expoliado”, según informó la prensa. ${ }^{40}$

El mes de junio de 1987, TV3 emitió el programa del concurso Vostè Jutja donde de modo ficticio se juzgaba a una persona que había "recogido" un ánfora del fondo marino sin haberlo comunicado a las autoridades. El argumento había sido propuesto por diversos arqueólogos con la colaboración de la Comisión de Patrimonio SCA, a fin de dar a conocer la gravedad de la generalizada expoliación que se estaba padeciendo. La audiencia y enorme popularidad de este concurso fue un eficaz instrumento de difusión y disuasión (Alay 2015: 85).

Significativo fue también el caso del Coll del Moro (Gandesa, Tarragona) (Hernández 1991: 115-122; Carrasco 1991: 25-26 y Cerdà 1991: 44-45). El 23 de julio de 1987 el equipo de excavación autorizada del yacimiento descubrió a dos arqueofurtivos con detectores de metales actuando en el mismo. A pesar de las dificultades con las que se encontraron para poder formalizar la denuncia (las autoridades no tenían claro que se tratara de un hecho delictivo), la tramitación del correspondiente expediente sancionador se calificó de modélica — según el Servicio Jurídico del Departamento de Cultura de la Generalitat- por dos razones:

a. Instrucción en tiempo récord -incoación de expediente sancionador en octubre de 1987 y resolución en marzo de 1988-.

$b$. El resultado desfavorable del recurso ante el Tribunal Superior de Justicia interpuesto por los imputados. La sentencia de 16 de marzo de 1990 afirmaba que el uso de un detector de metales en una zona notoriamente conocida como yacimiento arqueológico, a pesar de no estar señalizada, constituía una infracción administrativa.

La conjunción de todas estas acciones, incrementadas por las habitualmente llevadas a cabo por el Servicio de Arqueología del Departamento de Cultura catalán, motivó a partir de entonces un sensible decrecimiento de la actividad arqueofurtiva en Catalunya.

En 1988, arqueólogos, Guardia Civil y Policía Local de Écija sorprendieron a doce arqueofurtivos en la necrópolis ibérica del Cerro de las Balas. Se les denunció ante el Juzgado pero las diligencias se sobreseyeron porque la jueza "no apreció relevancia suficiente en los hechos para considerarlos delictivos" (Núñez y Muñoz 1988: 429; Rodríguez Temiño 2012: 1).

Entre los años 1992 y 1993 tuvo lugar en Extremadura uno de los primeros operativos policiales con implicaciones en buena parte de España e incluso en el extranjero: la denominada Operación Cigüeña. Se requisaron unas 570 piezas y fueron imputadas alrededor de 26 personas de las que únicamente 5 pudieron llevarse a juicio.

En primera instancia, en el año 2000, se condenó penalmente a dos imputados: dos meses a uno y un mes y un día al otro, imponiendo costas judiciales y obligando a devolver el importe de la venta de una

40. Diario Avui de 22 de mayo de 1987. 
pieza original manipulada (350.000 pesetas / 2.103,54€). En segunda instancia, la Audiencia Provincial de Badajoz estimó parcialmente el recurso de los condenados reduciéndoles la pena a un mes y un día para cada uno, pagar costas pero ya no tenían que devolver el dinero obtenido por la pieza (Contreras 2018: 218-219).

Sin abandonar la región, destacar el trabajo realizado por el Grupo de Delitos contra el Patrimonio Histórico Artístico de Extremadura, operativo entre 1994 y 1997. Intervinieron en muchos casos, como el del tesoro de Valdeobispo y el de la tumba de Botija (ambos en Cáceres) o el de Vegas Bajas del Guadiana (Badajoz). Las experiencias les permitieron realizar interesantes estadísticas y una tipología de los arqueofurtivos/coleccionistas activos en la zona (Enríquez y González 2005). ${ }^{41}$

En mayo de 1991 se celebraron en Barcelona unas Jornadas sobre protección legal del Patrimonio Arqueológico, organizadas por el Servicio de Cultura de la Diputación de Barcelona conjuntamente con la entidad Marc- $7^{42}$ y las colaboraciones de los Colegios de Licenciados y de Abogados. Se expusieron y analizaron algunos de los casos más relevantes, realizando propuestas ante la inminente ley de patrimonio de Catalunya (se acabaría promulgando en 1993) y la necesidad de las reformas penales prescritas por la Constitución de 1978. Destacar que en su aportación, la Brigada de Patrimonio Histórico de los Mossos d'Esquadra presentó la primera tipología conocida de los agresores del patrimonio arqueológico (Rodrigo 1991: 142-143).

En 1990 y 1991, la Escuela de Policía de Catalunya ofreció dos ediciones de un curso sobre protección del patrimonio histórico dirigido a mossos d'esquadra y policías locales. Se diseñó para "dotar a los agentes de una formación integral, tanto técnica como humanística, enseñándoles a identificar las diferentes técnicas artísticas, legislación sobre patrimonio y propiedad intelectual, nociones de historia del arte así como las medidas de protección y seguridad en los museos". Lamentablemente, esta pionera iniciativa no tuvo continuidad -al menos en un formato tan completo-. ${ }^{43}$

Precursor también fue el Curso sobre Protección del Patrimonio Arqueológico, celebrado del 23 al 25 de mayo de 1994 en Murcia. Organizado por la Conse-

41. Este grupo era una unidad del Cuerpo Nacional de Policía adscrita a la Comunidad Autónoma de Extremadura. Orgánicamente dependía del Ministerio del Interior pero funcionalmente de la Junta. Estadísticamente pudo comprobarse, por ejemplo, que casi el $60 \%$ de los arqueofurtivos sancionados en Extremadura entre 1990 y 1994 eran andaluces y que el 22,5\% de los mismos procedían de Lora del Río. Sus experiencias, así como una valoración de las mismas, fueron publicadas por Juan Javier Enríquez y Francisco González (Enríquez y González 2005).

42. Marc-7 fue un colectivo de opinión, conformado por arqueólogos, que en la segunda mitad de los ochenta y primera de los noventa realizaron diversas actividades y publicaciones relacionadas con la entonces incipiente profesión arqueológica y compleja situación jurídica del patrimonio arqueológico.

43. Artículo de Begoña Corzo, "Mossos y policías estudian cómo proteger el patrimonio artístico”, publicado en diario El Periódico el 5 de diciembre de 1990. jería de Cultura y Educación de la Región de Murcia iba expresamente dirigido a los cuerpos y fuerzas de seguridad del Estado. Asistieron 53 agentes -32 guardias civiles y 20 miembros del Cuerpo Nacional de Policía-, impartiéndose temas sobre legislación, nociones de arqueología y técnicas de investigación policial (Gimeno et al. 1996). ${ }^{44}$

\section{Período 1995 - 2015: el Código Penal}

El 24 de noviembre de 1995, el Boletín Oficial del Estado publica finalmente el nuevo Código Penal. Por primera vez se tipifican expresamente los delitos contra el Patrimonio Histórico. El artículo 323 castiga con una pena de prisión de uno a tres años y multa de doce a veinticuatro meses a quien cause daños en un yacimiento arqueológico (Alay 2015: 101-117). ${ }^{45}$

Hasta entonces la legislación penal hacía escasa referencia al Patrimonio Histórico. En el anterior y derogado Código Penal, de forma expresa prácticamente solo había un artículo, el 558, sobre daños, donde en su quinta circunstancia hacía referencia al "patrimonio histórico-artístico nacional". ${ }^{46}$ Aún así, la valoración del daño había de exceder las 250.000 pesetas $(1.502,23 €)$, para una pena de prisión menor. Por lo demás, constaba como circunstancia agravante del robo, hurto y de todos los hechos punibles comprendidos en el título de los delitos contra la propiedad y otras referencias indirectas. En la práctica, se traducía en una inaplicación del mismo, siendo desestimados o sobreseídos la mayoría de los casos que llegaban a plantearse por esta vía.

Durante este período se promulgan y desarrollan la mayoría de las legislaciones autonómicas, estructurándose a partir de las mismas los correspondientes expedientes sancionadores por actividades arqueofurtivas con sus luces y sus sombras. ${ }^{47}$

La ley estatal de 1985 no hace ninguna referencia a los detectores de metales y serán las leyes autonómicas las que tratarán la problemática aunque no de manera uniforme. Ignacio Rodríguez Temiño, uno de los autores que mejor conoce y ha tratado más a fondo la cuestión de los detectores y su incidencia arqueológica, distinguió entre dos modelos seguidos por las distintas comunidades (Rodríguez Temiño 2003):

44. En la publicación que resultó de este curso, se comenta que el mismo "es continuación de una tradición de cursos que impartía la Universidad, con un programa distinto, y con antelación al traspaso de competencias de la Administración central a la autonómica”.

45. Se han publicado diversas tesis doctorales sobre los artículos del Código Penal de 1995 relacionados con el patrimonio histórico y arqueológico. Destacan, Guisasola 2001; Renart 2002 y García Calderón 2016.

46. La inclusión del "patrimonio histórico-artístico" en la redacción del artículo corresponde a una reforma del Código de 1963. Esta reforma fue bastante polémica entre la doctrina, que entendía - entre otras cuestiones- solapamientos con el artículo 561 del mismo Código (Alegre 1994).

47. Sobre los desarrollos legislativos en las comunidades autónomas, pueden consultarse las colaboraciones publicadas en el libro El expoliar se va a acabar (Yáñez y Rodríguez Temiño 2018). Sobre procedimientos sancionadores en materia de patrimonio arqueológico, puede consultarse la tesis de Ana Yáñez Vega (Yáñez 2018). 
- Un primer modelo regula la finalidad arqueológica de la acción. Sanciona el uso no autorizado de los detectores con intención de realizar búsquedas arqueológicas. Debe probarse la intencionalidad. Es el caso de las comunidades de Castilla-La Mancha, Euzkadi, Castilla y León, Cantabria y Asturias.

- Un segundo modelo regula la finalidad arqueológica del aparato. Su uso debe ser expresamente autorizado, independientemente de la intencionalidad con la que se utilice. Es el caso de Andalucía, Galicia, Baleares, Aragón, Extremadura y Madrid. Se hacen habituales los cursos de formación dirigidos a los cuerpos de seguridad implicados, aunque no siempre ni en todas las comunidades han tenido la continuidad esperada. Ejemplo encomiable es la Junta de Castilla y León. En 1997 organizó, conjuntamente con el Ministerio de Educación y Cultura y la Dirección General de la Guardia Civil, unas Jornadas de Protección del Patrimonio Histórico celebradas en Ávila y que fueron posteriormente publicadas (Junta de Castilla y León 1997). En 2005 establecieron un convenio de colaboración con el Ministerio del Interior para la protección del patrimonio cultural de la comunidad, formalizando una adenda al mismo en 2006 por la que se comprometieron a la organización de cursos sobre protección de dicho patrimonio dirigido al personal de ambas administraciones (Escribano y Del Val 2018: 202-210).

Durante el verano de 1999 se puso en marcha desde la Generalitat de la Catalunya una campaña bajo el lema SOS, dirigida a submarinistas y pescadores (Nieto 2001: 102). En principio pretendía incentivar la declaración de los hallazgos subacuáticos casuales, pero también era una herramienta de concienciación de turistas y ciudadanos, así como un medio para facilitar las denuncias en caso de advertir algún expolio. En 2009 se sumaron a la iniciativa otras comunidades (Valencia y Andalucía) e instituciones españolas (Museo Nacional de Arqueología Subacuática), además de cuatro países europeos (Portugal, Francia, Malta e Italia). ${ }^{48}$

A partir de 1995 proliferan los operativos policiales y las causas judiciales - tanto administrativas como penales- empiezan a tener recorrido, dictándose las primeras sentencias condenatorias. Un repaso de las más significativas en orden cronológico nos permitirá ilustrar esta evolución.

El primer operativo ${ }^{49}$ del que he localizado información es la denominada Operación Mora. El 1995 la Guardia Civil intervino en la localidad de Moral de Calatrava (Ciudad Real) una importante colección arqueológica procedente, presuntamente, de expolios en yacimientos de la provincia. Las piezas, con una cronología que abarcaba desde el Paleolítico hasta la Edad Media, se encontraron en una casa de campo habilitada como museo. No he localizado ninguna

48. Artículo de prensa de Ferran Cosculluela, "SOS per l'espoli arqueològic del fons del mar", publicado en el diario El Periódico de Catalunya el 23 de mayo de 2009.

49. Salvo que se indique lo contrario, los datos relativos a los operativos relacionados se han extraído de Alay 2015: 142206). referencia a la resolución del caso. En la nota de prensa sobre el caso se dijo que el valor de lo hallado era incalculable y no fue posible determinar los yacimientos de procedencia. Estas circunstancias acaban siendo en la mayoría de las ocasiones las que hacen que los casos sean desestimados o archivados directamente.

En septiembre de 1999 se dio a conocer la Operación Trajano, también de la Guardia Civil. Se había detectado en una página web publicada en San José (California, Estados Unidos) la subasta de un lote de monedas romanas que presuntamente habían sido expoliadas en diferentes yacimientos andaluces. Se consiguió identificar y detener a un vecino de Almonte (Huelva). Fue la primera vez que en un operativo se vinculaba el expolio de los yacimientos arqueológicos con la venta de materiales en internet. Tampoco conozco la resolución, aunque es posible que no se lograra vincular las monedas con los yacimientos de origen ni determinar el momento del expolio, motivando el archivo de diligencias.

Entre los años 2000 y 2001 se produjeron las operaciones Zeus, Edetania y Júpiter en la zona de Valencia. Los tres operativos estaban relacionados. Los encausados se dedicaban, presuntamente, a la búsqueda y extracción incontrolada de materiales arqueológicos - monedas especialmente- que luego vendían a coleccionistas. El caso fue sobreseído, obligándose a devolver las piezas incautadas a sus "propietarios".

En el 2001 también se desarrolló un importante operativo para desarticular un grupo de personas dedicadas al arqueofurtivismo en Galicia. La investigación la dirigió la Policía Autonómica gallega, ${ }^{50}$ con la cooperación de la Policía Local de Lalín y el SEPRONA. Todo empezó con la expoliación de un castro en Lalín, pudiéndose identificar a un conocido arqueofurtivo -nunca antes se habían conseguido pruebas contra él-y relacionarlo con otros implicados -entre los que destacaba un cabo de la Guardia Civil-, conformando la que se denominó "red de Deza". Únicamente tres encausados fueron a juicio. Uno de ellos fue absuelto y la pena más alta para los condenados fue de un año y medio de prisión. Las sanciones económicas ascendieron a $5.760 € \mathrm{y}$ $2.880 €$. En segunda instancia se dejó como pendiente de ejecución la indemnización conjunta por daños al yacimiento, que ascendía a $180.315 €$.

En verano de 2001 se inició el primer gran operativo a nivel nacional, la Operación Tambora, llevado a cabo por la Guardia Civil. La primera fase se publicitó en febrero de 2002 dando a conocer el resultado del registro de dos cortijos, propiedad de Ricardo Marsal, donde además de miles de piezas se encontraron con un taller de restauración y un estudio fotográfico para catalogar las piezas. En julio del mismo año se dio por cerrado el operativo con ciento dos personas

50. Como en el caso extremeño, la Unidad de Policía Autónoma de Galicia es una unidad del Cuerpo Nacional de Policía adscrita a la Comunidad Autónoma de Galicia. Orgánicamente depende del Ministerio del Interior pero funcionalmente de la Xunta. 
investigadas y la recuperación de unas doscientas mil piezas. Se dijo que los yacimientos afectados eran más de quinientos y correspondían a Andalucía, Extremadura, Castilla-La Mancha, Murcia y Aragón.

Durante unos cuantos meses el SEPRONA había estado vigilando las entradas y salidas de personas a los dos cortijos, advirtiendo la presencia de vehículos que ya tenían "fichados" por pertenecer a personas implicadas en expolios. De esta forma consiguieron identificar a 142 presuntos arqueofurtivos.

La colección Marsal era muy conocida —empezó en los años setenta-, existiendo artículos y tesis sobre sus piezas. Ricardo Marsal había estado tratando con la Junta de Andalucía la cesión de toda su colección. En 1998 las negociaciones se rompieron ante las reticencias de la administración autonómica a hacerse cargo de la colección argumentando el condicionante jurídico derivado de la ilegalidad en la receptación de bienes procedentes de expolio. Entonces el coleccionista inició conversaciones con el Museo Arqueológico Nacional de Madrid. No falta quien opina que la razón del operativo tenga relación con la intención de evitar que la colección terminase fuera de Andalucía.

Sea como sea, en abril de 2005 la Junta acabó legalizando la colección al aceptar la donación de la totalidad de su contenido, incluidos los documentos que guardaban relación con lo que a partir de entonces era el Fondo Arqueológico Ricardo Marsal Monzón (FARMM). La Junta se quedó con todas las piezas, excepto las adquiridas en subastas públicas, que se las devolvió a Marsal, a cambio de abandonar la incoada vía judicial. Irónicamente el acuerdo también iba condicionado a un agradecimiento expreso por parte de la Junta, que hizo en el comunicado en que dio a conocer la cesión: "ha de agradecerse su gesto por su contribución al enriquecimiento del Patrimonio Histórico andaluz".

Polémica decisión, sin duda, la de priorizar la colección dejando perder la posibilidad de una sanción ejemplar. Muchos de los arqueofurtivos que desfilaron ante los agentes que vigilaron los accesos a los cortijos protagonizaron muchos de los operativos posteriores. Habría de preguntarse si no se hubiera recuperado más patrimonio neutralizando las actividades de todos ellos que aceptando las condiciones de Marsal a cambio de su descontextualizada y ya muy conocida e incluso estudiada colección. ${ }^{51}$

En 2002 la Operación Coja —de la Guardia Civil- desarticuló por primera vez una red de arqueofurtivos perfectamente estructurada que actuaba en yacimientos de Jaén y Córdoba. Un año más tarde, en 2003, la Guardia Civil y la Policía Local de Sevilla intervinieron en el mercado dominical que se celebra en la plaza del Cabildo de Sevilla y donde presuntamente se traficaba con piezas procedentes de expolio arqueológico, también presuntamente. En esta Operación Cabildo se recuperaron 3.564 de estas piezas, entre las que destacaba un importante lote numismático de 2.180 monedas.

51. Debe decirse, sin embargo, que esta colección en particular estaba muy bien documentada, permitiendo una serie de estudios que fueron publicados en 2014 por la Junta de Andalucía en un monográfico.
En octubre de 2005 la Guardia Civil tuvo conocimiento de que unas embarcaciones denominadas Gemini 3 y Maruk, vinculadas a otra de mayor tamaño, denominada Louisa, se encontraban expoliando por las costas de Cádiz y Huelva. Se inició la Operación Bahía. Bajo pabellón de la isla caribeña de Granada, tripulación húngara y propiedad de una compañía británica, pertenecía en realidad a un millonario tejano dedicado a la "caza de tesoros".

El viejo navío, construido en 1962, de unos cincuenta metros de eslora, había sido adaptado para la exploración submarina y pertrechado con sofisticados instrumentos de última generación. Se detuvo a tres personas y se requisaron los navíos Louisa y Gemini 3 -preparado con mangas para remover el fondo marino-, localizándose una importante cantidad de material arqueológico. Sorprendió encontrarse con cinco fusiles de asalto $\mathrm{M}-16$, sobre los que la tripulación explicó que servían para defenderse de los "buscadores de tesoros".

Tres meses más tarde se publicitó el resultado de la segunda fase del operativo, focalizada en la desarticulación de la red de expoliadores. Hubo detenidos en Sevilla, Madrid, Algeciras y Ciudad Real. Once de los encausados fueron a juicio, celebrado en abril de 2019. Se les condenó a pagar $540 €$ — cada uno de ellos-.

En febrero de 2007 se hicieron públicos los primeros resultados de la que se calificó como "la mayor operación contra redes de expolio arqueológico a nivel mundial": la Operación Tertis. Participaron más de 200 agentes de la Guardia Civil, se hicieron 68 registros domiciliarios y se detuvo a 52 personas. Entre los detenidos, había 30 arqueofurtivos, 13 intermediarios (numismáticos y anticuarios) y 9 coleccionistas — todos presuntamente- Se intervinieron más de 300.000 objetos arqueológicos. Eran tantas las piezas localizadas en algunos de los domicilios que, ante la imposibilidad de trasladarlos, se precintaron. En la rueda de prensa, todo el material mostrado procedía de un único domicilio sevillano. Había implicados en Sevilla, Huelva, Cádiz, Granada, Jaén, Córdoba, Madrid, Barcelona y Benavente (Zamora).

Lamentablemente el mes de de noviembre de 2009 se informó del sobreseimiento provisional y archivo de la causa, en primera instancia, para todos los encausados. Y en 2010 la Audiencia de Sevilla desestimó los últimos recursos de la Junta y de Fiscalía, argumentando que "no puede ignorarse la imposibilidad de acreditar tanto el origen de los objetos o restos arqueológicos incautados (...) como el concreto momento de su aprehensión material (...) así como el carácter lícito o ilícito de su adquisición”.

Se procedió a la devolución de las piezas a sus "legítimos propietarios" — como ordenaba el autoentre ellos "empresarios y médicos" de Madrid y Barcelona.

También en 2007 ocurrió la mediática Operación Casiopea, más conocida como el caso Odyssey. La empresa norteamericana Odyssey Marine Exploration estaba supuestamente desarrollando un proyecto consistente en búsqueda del pecio inglés Sussex, en el mar de Alborán. Con este pretexto estaba en realidad cartografiando el fondo marino para localizar todo tipo de pecios, cuya carga les pudiera interesar. 
Entre los meses de febrero y mayo de 2007 se detectaron una serie de extrañas salidas de sus buques durante las que apagaban sus sistemas de posicionamiento. A partir de abril empezaron a solicitar licencias de exportación a las autoridades de Gibraltar para "monedas", "artefactos antiguos de bronce” y otros efectos. Más tarde se supo que habían localizado e iniciado el expolio del pecio español de Nuestra Señora de las Mercedes.

Se realizaron diversos registros en los buques y se intervino documentación. Tras un largo proceso judicial, las autoridades americanas ordenaron que los bienes expoliados fueran devueltos al gobierno español. Finalmente, en febrero de 2012 dos aviones de las fuerzas aéreas españolas los transportaron de vuelta. Este caso fue muy mediático y sirvió para dar a conocer la gravedad del expolio arqueológico subacuático (Guasch 2018: 423-430).

En abril de 2008, el Cuerpo Nacional de Policía dio a conocer los resultados de la denominada Operación Pitufo. Las investigaciones se iniciaron a raíz de las informaciones obtenidas en dos operativos anteriores (Vivo y Lirio). Tuvo alcance estatal, aunque finalmente se focalizó en las comunidades andaluza y valenciana.

Los implicados se dedicaban casi exclusivamente al expolio, receptación y coleccionismo de material arqueológico, realizando la mayoría de transacciones por internet.

Hubo veinte detenidos y se recuperaron unas diez mil piezas arqueológicas. En uno de los veinticuatro registros domiciliarios, concretamente en Jaén, fueron necesarias tres furgonetas para transportar el material intervenido hasta el depósito correspondiente.

Entre los instrumentos y la documentación, destacan ocho detectores de metales, un visor nocturno, supuestos certificados de autenticidad y una guía muy especial. Uno de los implicados estaba en posesión de lo que resultó ser un auténtico manual con consejos de comportamiento ante eventuales acciones policiales.

La sentencia se conoció en 2015. Las cinco personas finalmente encausadas fueron absueltas. Según la sentencia no se aportaron pruebas suficientes para desvirtuar la presunción de inocencia de los inculpados. La jueza destacaba que habría sido esencial un informe pericial que determinara la cronología, procedencia exacta y valoración de las piezas intervenidas. La Junta de Andalucía manifestó la imposibilidad de hacerlo por falta de medios técnicos y personales.

En 2009 se dio a conocer el caso Petrus de Castellum. Hasta la fecha era el operativo más importante de los realizados por los Mossos d'Esquadra contra el expolio arqueológico. Se inició al tenerse conocimiento de la venta de material arqueológico — que podía tener procedencia ilícita - a través de distintos portales de internet. Tenían clientes en Estados Unidos, Francia, Italia, Alemania, Nueva Zelanda...

Se verificó la actuación de los presuntos responsables en yacimientos ubicados mayoritariamente en comarcas de Lleida. Se llevaron a cabo seis registros en domicilios de Catalunya y otro en Albacete, practicándose ocho detenciones. Se decomisaron unas quince mil piezas arqueológicas.

Los Mossos manifestaron que "los detenidos expoliaban lugares especialmente protegidos siendo conscientes que estaban llevando a cabo una actividad ilícita. La venta de este material por parte de los arrestados era reiterada y algunos de ellos, viendo los importantes beneficios que conseguían, tenían pensado dedicarse exclusivamente a la expoliación". Se calculaba que uno de ellos había conseguido, desde mayo de 2008, entre 60.000 y $70.000 €$ con esta actividad.

En 2009 se llevó a cabo, por la Guardia Civil, la Operación Badia para desarticular a un grupo de personas dedicadas al arqueofurtivismo en la provincia de Cáceres. Las investigaciones pusieron de manifiesto la existencia de un grupo organizado. Cada uno de sus componentes tenía asignadas funciones bien delimitadas. Casi todos se dedicaban al arqueofurtivismo, que para algunos constituía su "quehacer casi diario", e iban a yacimientos con detectores y herramientas, incluso de noche. Uno de ellos daba salida a los objetos obtenidos y los vendía por internet, tanto a coleccionistas españoles como extranjeros. Cerrada la venta, remitía los objetos a los compradores por correo ordinario certificado o empresa de mensajería.

La negativa experiencia de la Operación Tertis propició un cambio en los métodos de investigación. Esta vez a los seguimientos de los arqueofurtivos se incorporó la diligencia de documentar la acción arqueofurtiva tomando imágenes de los autores en acción, después se realizaba una primera inspección ocular de las remociones y finalmente una segunda inspección con los técnicos de cultura para su valoración.

En fase de explotación se realizaron seis registros domiciliarios, deteniendo a siete personas, investigando a cuatro más y recuperando unos 75.000 objetos arqueológicos.

La sentencia de 2014 condenó a los diez que fueron finalmente procesados, con penas de entre un año y año y medio de prisión, además de las penas accesorias (inhabilitaciones del derecho de sufragio pasivo y multas) y sanciones pecuniarias por responsabilidad civil.

Esta sentencia fue pionera por el hecho de ser la primera, en todo el ámbito estatal, en condenar con penas de prisión a un grupo organizado de arqueofurtivos. Había antecedentes de sentencias penales condenatorias con penas similares (la de la denominada red de Deza, en 2005, y la de los detectoristas de Acinipo, en 2009, por ejemplo) pero nunca referidas a un grupo. El éxito se debió, fundamentalmente, a que fue posible vincular los materiales arqueológicos extraídos con los yacimientos de origen y con cada uno de los autores, así como valorar exactamente -donde, cuándo y por quién- los daños causados.

La misma metodología de investigación se aplicó a la Operación Necrópolis, también de la Guardia Civil y desarrollada en las comunidades de Valencia y Castilla-La Mancha. Se saldó con la detención de doce personas (diez presuntos arqueofurtivos y dos intermediarios), el registro de trece domicilios y la recuperación de unos nueve mil objetos arqueológicos. Los diez arqueofurtivos pertenecían a un mismo clan familiar y se verificó que realizaban muchos actos de precaución (actuaciones nocturnas, elección de lugares despoblados, utilización de distintas vías de acceso...) con lo que delataban tener conocimiento de la ilegalidad de sus acciones. 
En 2018 la resolución judicial —confirmada en segunda instancia un año más tarde- condenó a ocho encausados por un delito de hurto a penas de entre un año y veinte meses de prisión. A los dos encausados por receptación se les condenó a seis y dieciocho meses de prisión. Accesoriamente se les condenó a devolver las piezas y al pago proporcional de las costas.

Estos casos, Badia y Necrópolis, llevan a colación otros que a pesar de no estar vinculados entre sí sugieren la intervención de grupos similares con modos de actuación análogos y en expansión por todo el territorio estatal.

Me refiero a los robos del emblema de uno de los grandes mosaicos de la villa romana de Santa Cruz (Baños de Valdearados, Burgos) en 2011; del sillar romano con relieves fálicos de Clunia (Burgos), en 2011; del busto romano de la iglesia de Quintana del Marco (León) en 2013, y del emblema de un mosaico de la villa romana de Río Verde (Marbella) en 2016.

Si bien se trata de robos en yacimientos o monumentos, con más o menos protección, y por tanto no se trata de acciones arqueofurtivas, los modus operandi sugieren la intervención de grupos de personas con experiencia en las mismas. De todos ellos únicamente se resolvió el de León (Operación Versus), resultando ser los autores un grupo de personas, domiciliadas en Alcolea del Río y Brenes (Sevilla), con antecedentes por arqueofurtivismo en Andalucía y Castilla y León.

Habida cuenta de que todas las piezas sustraídas son muy conocidas y han sido ampliamente difundidas, difícilmente puede negociarse con ellas sin que en algún momento se descubra su origen. En consecuencia, se apunta a robos por encargo (loot to order) en los que pueden estar implicados grupos organizados habitualmente dedicados al arqueofurtivismo y que puntualmente pueden actuar en cualquier punto del territorio estatal.

La finalidad de la Operación Piteros fue preventiva: concienciar sobre la importancia del patrimonio arqueológico y dar a conocer los límites legales al respecto. En octubre de 2012, el SEPRONA comunicó haber llevado a cabo un total de 1.649 servicios en 19 provincias. Se realizaron 751 inspecciones, identificando a 139 personas y formulando 67 denuncias administrativas de las que 31 se relacionaban con el patrimonio histórico.

El dispositivo también se extendió al litoral, donde se identificaron diez embarcaciones. La actuación en este ámbito se intensificó con la Operación Ánfora, dada a conocer en 2013. En dos semanas, más de 1.500 agentes de la Guardia Civil llevaron a cabo 248 inspecciones en 17 provincias.

Es posible que este operativo facilitara mucha información que meses más tarde permitió cerrar la Operación Circinus. Desde junio de 2010 se tenían indicios de que la fundación privada Argo Maris, domiciliada en Terrassa (Barcelona), se dedicaba presuntamente al expolio de yacimientos submarinos.

Esta fundación, que había colaborado en la elaboración de las cartas arqueológicas submarinas de Catalunya, disponía de dos embarcaciones — de 18 y 23 metros de eslora- perfectamente equipadas. Se realizaron un total de quince registros y se detuvo a diez personas. Se relacionaban con los pescadores, quienes les informaban sobre posibles yacimientos y que después recibían algunas de las piezas expoliadas en compensación. Operaban principalmente por la Costa Brava y Menorca.

En junio de 2014 se llevó a cabo la segunda fase de la Operación Ánfora. Intervinieron más de 1.500 efectivos de la Guardia Civil que realizaron 597 inspecciones en las 25 provincias litorales. Sin embargo, ninguna de las 39 infracciones administrativas detectadas tenía relación con el patrimonio histórico.

No es posible finalizar este repaso por las operaciones policiales más significativas de este período sin referirse a la Operación Helmet. Aunque se dio a conocer en 2013 sus orígenes se remontan a los años setenta del siglo pasado.

Entre 1975 y 1976, en el transcurso de sus actividades arqueofurtivas en el entonces casi desconocido yacimiento de Arakitos en Aranda de Duero (Zaragoza), el principal encausado se encontró lo que denominó "placas". Un anticuario suizo de origen español, las iba adquiriendo y después de hacerlas restaurar se convirtieron en los excepcionales dieciocho cascos de bronce que eran en realidad. Se subastaron y fueron adquiridos por un coleccionista austríaco.

El arqueofurtivo siguió expoliando Arakitos. En 1992 con una pala excavadora cargó un camión y, literalmente, se llevó parte del yacimiento para seguir "excavándolo" tranquilamente en su casa. El Ayuntamiento paralizó la "obra”, denunciándolo al Gobierno de Aragón, que envió a un arqueólogo. No he podido saber nada más. Hasta el momento únicamente se había documentado la utilización de maquinaria pesada para actividades arqueofurtivas en la Operación Edetania (2001) y en el castro de Palio en Lalín (2001) —en relación con la reseñada red de Deza-, pero nunca de esta magnitud.

Según manifestó el encausado, dejó de salir al campo con el detector de metales entre 1997 y 1998, poco antes de casarse con su segunda mujer, hija de guardia civil, ya que su manifiesta actividad "causaba problemas”. De ser cierto, actuó más de veinte años con absoluta impunidad.

El coleccionista austríaco falleció y sus herederos se desprendieron de su inmensa colección. Los cascos se subastaron repartiéndose por el mundo ante la pasividad de las autoridades españolas. En 2009, el Ministerio de Cultura intentó algunas gestiones que se archivaron judicialmente por falta de pruebas. No fue hasta 2011 que intervino la Fiscalía de Medio Ambiente y Urbanismo del Tribunal Supremo, iniciándose la Operación Helmet.

Tras una ardua investigación, la Guardia Civil identificó y detuvo al arqueofurtivo. Se recuperaron más de cuatro mil piezas, además de seis detectores de metales y un georadar.

La documentación intervenida permitió una segunda fase del operativo, identificando a otro presunto arqueofurtivo que había colaborado con el primero. Esta persona, a pesar de no tener estudios oficiales en Arqueología, era considerada experta en el período celtíbero, habiendo impartido conferencias, participado en congresos y en proyectos arqueológicos. 
El juicio se celebró en abril de 2018 y la sentencia resultó condenatoria para ambos encausados. Al arqueofurtivo de Arakitos le condenaron a seis años de prisión - tres años por un delito continuado de daños materiales intencionados sobre yacimiento arqueológico en concurso con un delito continuado de hurto y a tres años más por otro delito continuado de blanqueo de capitales- y al segundo a tres años de prisión por un delito continuado de blanqueo de capitales cometido "durante más de veinte años". La sentencia ha sido recurrida por los encausados.

En la última fase del período que nos ocupa, empezaron a incorporarse a la lucha contra el expolio arqueológico los Agentes Rurales, Guardas Forestales, Agentes Medioambientales... —-distintas denominaciones según la Comunidad Autónoma que se trateUno de los primeros fue el Cuerpo de Agentes Rurales en Catalunya, con actuaciones puntuales desde 2008 que se hicieron más comunes a partir de 2012 con la formalización de un convenio con la Dirección General de Patrimonio Cultural de la Generalitat. Su implicación ha sido cada vez mayor y relevante, especialmente en la identificación y denuncia de los arqueofurtivos que utilizan detector de metales (Picón 2018). Este incremento de actuaciones también se advierte en otras comunidades, como se aprecia a través de los medios de comunicación que periódicamente informan sobre las mismas.

\section{A partir de 2015: arqueocibertráfico}

En 2015 entró en vigor una modificación del Código Penal que afectó muy especialmente al artículo 323 , introduciendo en el texto el término expolio. Tomando en consideración algunas de las muchas críticas doctrinales se incluyó por fin un concepto definido por la legislación administrativa del patrimonio histórico.

Siendo los arqueofurtivos un tipo de expoliadores de los yacimientos arqueológicos, puede afirmarse que con esta nueva adición se tipifica el arqueofurtivismo, junto con otros tipos de expolio que se puedan causar en los mismos. Circunstancia que abre nuevas expectativas en la lucha contra las actividades que nos ocupan y por tanto un nuevo período.

Sin embargo, salvo algunas excepciones, la doctrina jurídica no considera admisible equiparar el concepto administrativo de expolio - artículo 4 de la Ley 16/1985- con el penal. Uno de las principales polémicas viene motivada por el hecho de que el expolio administrativo se define a partir de conductas no consumadas (“...ponga en peligro de...”) y en procedimiento penal difícilmente puede asumirse un concepto basado principalmente en tentativas o hechos frustrados, debiendo establecer claramente la consumación efectiva de los mismos. Esta y otras razones motivan que todavía no se haya llegado a un acuerdo sobre el alcance penal del expolio.

Este nuevo período - a partir de 2015- viene definido también por el arqueocibertráfico. La mayoría de los arqueofurtivos utilizan este medio para sus transacciones. Además se consolida un nuevo tipo de arqueofurtivo $^{52}$ que hasta el momento solo aparecía puntualmente: el Traficante Completivo Autosuficiente. Exploran y remueven exclusivamente para vender los hallazgos con afán de lucro inmediato (traficantes), como complemento a su ocupación habitual (completivos). A diferencia de los grupales (que habían predominado hasta ahora) actúan en solitario. Son ellos mismos quienes buscan las piezas y gestionan la venta con los intermediarios o destinatarios finales, generalmente por arqueocibertráfico. Tristemente, además de las redes darknet y deepnet también se han verificado casos en aplicaciones como Wallapop..$^{53}$

Desde 2015 he documentado casi cincuenta operativos de los distintos cuerpos y fuerzas de seguridad sobre arqueofurtivismo - puede haber más- y otras tantas actuaciones que sin llegar a calificarse como "operación" tienen —en su medida - igual transcendencia. Entre todas, reseñaré las que he considerado más significativas.

El caso Isurus se inició en 2016 al detectarse que una empresa se dedicaba a la venta por internet de materiales arqueológicos y paleontológicos, además de libros y antigüedades. Se comprobó que su actividad en las plataformas - las más habituales en el comercio minorista por la red- era muy intensa. En las ofertas se indicaba además el yacimiento del que procedía cada una de las piezas, principalmente catalanes y andorranos. También era evidente que muchos de los materiales ofertados eran falsificaciones.

Después de un año de investigaciones, en 2017 los mossos de la Unidad Central de Patrimonio Histórico detuvieron en Amer (Girona) a dos personas. En los registros se intervino gran cantidad de material arqueológico y paleontológico, documentación y un detector de metales. En diversas estancias del domicilio se encontraron centenares de piezas, mayoritariamente paleontológicas, con fichas en las que se indicaba lugar de origen con las fechas de localización y extracción. También tenían un taller en el que, a partir de cantos rodados que recogían, fabricaban las herramientas supuestamente neolíticas que luego vendían. Así mismo se encontraron diversos artículos etnológicos africanos, contemporáneos, que "transformaban" en material prehistórico.

52. Fundamentalmente mi propuesta tipológica de los arqueofurtivos se publicó por última vez en la aportación al libro $E l$ expoliar se va a acabar (Alay 2018: 63-66). Desde entonces, ha evolucionado en algunos aspectos - especialmente terminológicos- que todavía no se han publicado.

53. Casos en la aplicación Wallapop son, por ejemplo, el de un cuello de ánfora romana "auténtico" que se vendía por $550 €$ (noviembre 2016) y el de una moneda procedente del yacimiento de Empúries (Girona) que quien la expolió hace más de treinta años pretendía venderla por $75 €$ (marzo 2018). En ambas ocasiones, intervinieron los Mossos d'Esquadra y se recuperaron las piezas. Una muestra muy ilustrativa sobre las dimensiones del arqueocibertráfico es el recientemente publicado (junio 2019) Informe del proyecto ATHAR, Facebook's black market in antiquities. Trafficking, Terrorism and War Crimes, de Amr Al-Azm y Katie A. Paul. Realizado un seguimiento de este tráfico en Próximo Oriente se identificaron 95 grupos de Facebook con 1.947.195 miembros y 3.539 entradas registradas. Cabe decir que se ha verificado que parte de las piezas ofertadas son falsificaciones, algunas muy evidentes (hasta el momento no hay datos sobre su porcentaje). 
Análisis posteriores verificaron que además de las falsificaciones había material auténtico. Se encontraron evidencias del expolio de 168 yacimientos arqueológicos y 32 paleontológicos, ubicados en gran parte en el área prepirenaica. Se verificó que los beneficios obtenidos en siete meses en una de las plataformas - utilizaban cuatro- ascendían a una media de $1.000 €$ mensuales. ${ }^{54}$

Lo más lamentable del caso es que los autores resultaron ser dos hermanos con titulación universitaria de arqueología y geología. Ambos habían participado en excavaciones, escrito artículos e impartido conferencias.

En 2018 el Cuerpo Nacional de Policía dio a conocer la Operación Harmakis informando sobre el desmantelamiento de una red que comerciaba con piezas arqueológicas expoliadas en Libia. Se practicaron cinco registros y se detuvo a dos personas en Barcelona. Uno de ellos era un conocido anticuario barcelonés especializado en la venta de material arqueológico.

Los detenidos formaban supuestamente parte de una red con base en Catalunya y ramificaciones internacionales que se dedicaba a la adquisición y venta de bienes arqueológicos procedentes de territorios que se encontraban en la zona de influencia de DAESH. Se servían de intermediarios que buscaban y adquirían las piezas realizando el envío a través de terceros países de Oriente Medio y Asia.

Se manifestó que era "la primera operación desarrollada en el mundo contra la financiación del terrorismo a través del expolio de obras de arte de territorios bajo el asedio de grupos terroristas". ${ }^{55}$

En los registros efectuados se localizaron las fotografías de tres piezas íberas que se buscaban desde 2017 al sospecharse que habían sido expoliadas en un lugar indeterminado de Jaén o Córdoba. Junto con la documentación que también se encontró pudo cerrase la denominada Operación Leona. De este modo se desarticuló una presunta red que traficaba con bienes arqueológicos expoliados en España. Una de las piezas se vendió - falsificando la documentación- a un conocido matrimonio de banqueros - que la compraron ignorando su origen ilícito-. Lo lamentable es que, entre los cinco detenidos, se encontraba un conocido arqueólogo que habría participado - presuntamenteen la confección de la documentación con la que se pretendió blanquear la pieza. ${ }^{56}$

Finalmente, una referencia a la macro Operación Pandora. Es un gran operativo internacional, con antecedentes en la Operación Aureus -llevada a cabo en 2014-, del que hasta la fecha se han dado a conocer tres fases.

54. Informaciones a partir de las notas de prensa del Área de Comunicación de los Mossos d'Esquadra de 2 de septiembre de 2017 y 10 de enero de 2018.

55. Informaciones a partir de la nota de prensa de la Delegación del Gobierno en Catalunya de 28 de marzo de 2018.

56. Artículo de Daniel Montero, "Operación Leona: cinco detenidos en una red de tráfico de arte que engañó a una hija de Emilio Botín", publicado en el diario El Español el 9 de enero de 2019.
La primera, desarrollada en 2016, se centró - conforme se indica en la nota de prensa facilita$\mathrm{da}^{57}$ - "en el expolio cultural (tanto en el mar como en tierra), el tráfico ilícito de bienes culturales (con especial atención a los bienes procedentes de países en conflicto) y el robo cultural con el fin de mejorar el conocimiento sobre los grupos delictivos que se dedican a ello e identificar los posibles vínculos con otras áreas criminales". Participaron dieciocho países europeos, liderados por España y Chipre, con el apoyo de Europol, Interpol, la UNESCO y la Organización Mundial de Aduanas (OMA). Se saldó con 75 detenidos y propició la apertura de 92 nuevas investigaciones en la materia.

La segunda fase se desarrolló en 2017, siendo liderada por la Guardia Civil y Europol, realizándose de manera combinada con la Operación Athena de la OMA. Conforme lo informado "se realizaron decenas de miles de controles en aeropuertos y pasos fronterizos de 81 países que participaron -Athena tenía alcance mundial-, se inspeccionaron comercios y tiendas de antigüedades, galerías de arte, salas de subastas y museos con el resultado final de un total de 101 detenidos y más de 300 investigaciones abiertas”. Se realizó una especial vigilancia de los sitios web de compraventa -interviniéndose por esta vía más de 7.000 objetos, casi el $20 \%$ de los bienes recuperados-. ${ }^{58}$

Finalmente en agosto 2019 se dio a conocer la tercera fase. Fue liderada y coordinada por la Guardia Civil junto con Europol, Interpol y la OMA, participando fuerzas de seguridad de 29 países. Se incautaron más de 18.000 bienes culturales entre obras de arte, piezas arqueológicas, muebles, monedas, pinturas, instrumentos musicales y esculturas. En cuanto a la materia que nos ocupa, entre el 22 y el 30 de octubre de 2018, se realizaron 7.170 inspecciones en yacimientos arqueológicos, donde se detuvieron a seis personas, se interpusieron 49 sanciones administrativas y se incautaron 909 bienes culturales. ${ }^{59}$

Este operativo es un ejemplo de coordinación internacional entre distintas fuerzas de seguridad y administraciones.

\section{Acabar con el arqueofurtivismo: reflexiones y propuestas}

No es fácil, más bien todo lo contrario, terminar con una actividad que, como hemos visto, tiene sus raíces en los albores de la humanidad. No es excusa, sin embargo, para dejar de combatirla. Será más bien complicado "acabar con el expolio" — como se decidió titular la última monografía publicada sobre el tema en España (Yáñez y Rodríguez Temiño 2018)— pero sí es posible minimizarlo.

En las líneas que anteceden se ha realizado un repaso, no pormenorizado sino más bien ilustrativo,

57. Nota de prensa conjunta del Ministerio del Interior español y Europol de 22 de enero de 2017.

58. Nota de prensa de la Guardia Civil de 21 de febrero de 2018.

59. Nota de prensa conjunta del Ministerio del Interior español, Europol, Interpol y la OMA de 6 de agosto de 2019, emitida en La Haya (Países Bajos). 
de algunos de los hechos más significativos del arqueofurtivimo español y de los esfuerzos para eliminarlo. Estas y otras muchas experiencias que han quedado en el tintero deben servirnos para afrontar el reto y plantear soluciones.

En la actualidad los procedimientos administrativos y penales suelen resolverse y, en general, no se sobreseen y archivan de forma habitual como ocurría no hace tantos años. Sin embargo, las sanciones o penas no se ajustan - a nuestro entender- al daño realmente causado. Hemos visto como hace pocos meses, se ha condenado a únicamente $540 €$ a los encausados por la Operación Bahía, después de casi veinte años de diligencias. Debe seguir trabajándose para conseguir una ajustada proporcionalidad sancionadora.

En este sentido, es muy buena noticia la aplicación del método de investigación utilizado por primera vez en la Operación Badia. Debería insistirse en la normalización de esta metodología o protocolo - que podríamos denominar Badia- así como adaptarlo o elaborar otros nuevos que permitan su aplicación en las distintas situaciones que puedan plantearse.

La jurisprudencia ha demostrado que la falta de indicios ha sido determinante en el resultado de muchos casos. Es evidente que su recolección y análisis en los lugares de los hechos deben introducirse en los protocolos policiales (Alay 2017). En la actualidad, está en desarrollo un proyecto de investigación académica sobre arqueometría forense (Rodríguez Temiño et al. 2018) a partir del que probablemente se desprenderán propuestas a tener muy en cuenta en la elaboración de dichos protocolos.

También es necesaria la elaboración de protocolos dirigidos a los arqueólogos. Especialmente los titulares de una autorización de intervención arqueológica, deberían disponer de unas pautas de actuación en los supuestos de actividad arqueofurtiva. Con los mismos se podrían evitar interferencias y gestiones reiteradas, agilizando e incrementando sensiblemente la eficacia de las diligencias policiales, administrativas y penales (Alay 2015: 381-383).60

La valoración económica de los daños es decisiva. Las actividades arqueofurtivas $-\mathrm{y}$ todas las expoliadoras- además de los daños materiales destruyen valores que son difícilmente cuantificables. Aunque parte de la doctrina jurídica se ha manifestado a favor de introducir modificaciones para la admisión de los daños incalculables, todavía estamos muy lejos. Mientras tanto, las valoraciones deben tenerlo en cuenta para resultar realmente proporcionales al daño realmente causado. Distintos autores -muy pocos por cierto- han publicado sus propuestas pero es imprescindible trabajar en un baremo que sea generalmente aceptado, tanto por los arqueólogos como por las autoridades administrativas y judiciales (Rodríguez Temiño 2012: Anexo 2, 2017 y 2019; Alay 2015: 388-400 y Romeo et al. 2017).

60. En 2008, a propuesta del Servei d'Arqueologia i Paleontologia de la Generalitat de Catalunya, elaboré un borrador de protocolo. La finalidad era facilitarlo junto con las autorizaciones de intervención. Lamentablemente, una serie de cambios internos motivados por resultados electores no hicieron posible que la idea prosperase.
El concepto de expolio, finalmente introducido en el Código Penal a partir de 2015, es motivo de controversia doctrinal. Personalmente soy partidario de mantener el vínculo con la definición administrativa (artículo 4 de la Ley 16/1985). Entiendo que debería proponerse una modificación en dicha definición, llegando a un consenso de modo que se ajuste a las premisas penales sin menoscabar las administrativas.

Hasta la fecha no he sabido localizar ninguna explicación sobre la génesis del actual concepto administrativo. Salvo que la haya, creo que los autores se limitaron a acordar una definición contrapuesta al contenido del artículo 1, donde se concreta el objeto de la Ley. Probablemente no será suficiente con cambiar "ponga en peligro de" por "cause", dado que seguiríamos ocasionando dudas sobre cuáles son los "valores que integran" el patrimonio histórico, con la consiguiente merma de seguridad jurídica. ${ }^{61}$ Es imprescindible acordar un concepto.

La impunidad de los años ochenta ocasionó que algunos arqueólogos entraran en connivencia con los arqueofurtivos - tal y como hemos referido en su momento - a cambio de poder estudiar o publicar determinadas piezas o evitar el expolio de determinados yacimientos. Todavía hay quien persiste en este tipo de prácticas. En la actualidad, habiéndose tipificado el arqueofurtivismo - todavía nos falta recorrido pero los avances son significativos- la solución pasa por calificarlas de complicidad o encubrimiento — -según los casos-, ser investigadas y sancionadas como tales.

Otro espinoso asunto es el de los detectores de metales. Siempre he defendido que el "arma" más peligrosa del arqueofurtivo es la herramienta (azada, pala...) y no el aparato. Con la primera se remueve el suelo, mientras que el segundo solo hace ruido. Precisamente su aparatosidad y ruido facilitan su identificación y, en consecuencia, pasan a engrosar las estadísticas del expolio. No olvidemos, sin embargo, la cifra negra constituida por el arqueofurtivismo que sabemos existe pero que al no ser identificado no aparece en las estadísticas. Hay arqueofurtivos que nunca han utilizado un aparato detector de metales o similar y no se pueden obviar.

Dicho esto, es innegable la existencia de la problemática ocasionada por los arqueofurtivos usuarios de los detectores. Como hemos visto, han motivado múltiples reacciones, normativas y resoluciones. El tema sigue sin resolverse. La última propuesta legislativa, todavía pendiente de aprobarse, apuesta por la prohibición total del uso lúdico de los reiterados aparatos. Parte de la Junta de Andalucía y otras comunidades no ven con malos ojos gestionar su implementación. El conflicto con los colectivos que consideran la detección metálica una afición está garantizado.

Personalmente creo que esta problemática entrará en vías de solución cuando consigamos la reiterada proporcionalidad sancionadora, independientemente de regular la finalidad de la acción o el uso del aparato. La legislación administrativa prevé elevadas

61. La "perturbación del cumplimiento de su función social" no es problema ya que fue aclarada por los jueces en la sentencia de 1991 que resolvió sobre los recursos constitucionales. 
sanciones económicas (que por cierto, pocas veces se han actualizado desde su promulgación) y la penal unos cuantos años de prisión. Muy pocos arqueofurtivos, por no decir ninguno, han satisfecho sanciones o penas que se acerquen a los límites legales. Hay margen para ajustar la proporción.

Desde principios de los noventa las administraciones han apostado por la formación dirigida a las fuerzas de seguridad. Esta herramienta ha demostrado su eficacia y debería potenciarse todavía más, impartiéndose en todas las academias y escuelas de los futuros agentes.

La propuesta no es nueva - recordemos los cursos de la Escuela de Policía de Catalunya de 1990 y 1991pero ahora ya no debería ser un seminario más o menos voluntario sino que debería estar integrado en los programas obligatorios. Con un patrimonio cultural tan inmenso como el nuestro - actualmente España es el tercer país del mundo con más patrimonio de la Humanidad declarado-, todos y cada uno de los agentes deberían disponer de unos conocimientos básicos en la materia, independientemente de si con posterioridad sus destinos se relacionan o no con los casos que nos ocupan - naturalmente, en caso afirmativo, la formación debería ser mayor-. Estas medidas no implican la supresión de los cursos que se vienen realizando en diversas comunidades. Seguirían manteniéndose, pero su finalidad ya no sería la de facilitar conocimientos sino actualizarlos — cursos de reciclaje-.

A estas alturas resulta incomprensible que el arqueofurtivismo sea ignorado en las formaciones universitarias. La realidad es abrumadora: en una encuesta efectuada por Blytthe Bowman a 1.835 arqueólogos distribuidos en 101 países, el 97,7 \% respondieron haber sufrido expolio en los yacimientos en los que trabajaban o habían trabajado (Bowman 2011: 505-506; Balcells 2018: 344). Sin embargo, nuestros futuros arqueólogos apenas reciben algún comentario, limitándose sus conocimientos a las experiencias que puedan o no tener en los yacimientos donde realizan las prácticas.

Siendo un tema de tanta trascendencia para la profesión, en los grados de Arqueología debería ser preceptivo ofrecer un mínimo de conocimientos. En los últimos tres cursos he tenido la experiencia de impartir un seminario ${ }^{62}$ dirigido a los alumnos de grado de la Universidad de Barcelona. El resultado es óptimo y las nuevas generaciones terminan sus estudios sabiendo al menos qué es el arqueofurtivismo, cómo actuar frente al mismo y nociones sobre su valoración económica. Así mismo se incentiva su investigación académica — trabajos de fin de grado o máster, tesis doctorales...-.

Como ya he manifestado con anterioridad (Alay 2015: 508), el estudio e investigación académica del arqueofurtivismo es muy incipiente, ofreciendo muchas y diversas posibilidades. Aunque se consiguiera erradicarlo siempre habrá alguna vía que permita profundizar en su conocimiento.

Joan Carles Alay i Rodríguez

Doctor en Arqueologia. Responsable de la Comissió de Patrimoni de la Societat Catalana d'Arqueologia (SCA). Investigador del Seminari d'Estudis i Recerques Prehistòriques (SERP) de la Universitat de Barcelona. Director d'Investigació de la Sociedad Española de Investigación de Perfiles Criminológicos (SEIPC). joancarlesalay@yahoo.es

Data de recepció: 17/09/2019 Data d'acceptació: 13/11/2019
62. Incluido en el programa de la asignatura de Gestión del Patrimonio Arqueológico. 
ABAD, L. y Amorós, V. (2017). La cerámica griega, ¿elemento de prestigio en época visigoda?: El caso de El Tolmo de Minateda (Hellín, Albacete). En: Homenatge de Glòria Trias Rubiés. Cerámicas griegas de la península Ibérica: cinquanta anys després (19672017). Centro Iberia Graeca. Barcelona: 63-72.

Adell, J. A.; Dupré, X.; Granados, J. O.; Nieto, X.; Pérez, A. y Rafel, N (1984). Ponència en el Col-loqui sobre la Protecció del Patrimoni Arqueològic celebrado en Barcelona el 3 de marzo de 1984. Archivos de la Societat Catalana d'Arqueologia. Inédito.

Alay, J. C. (1990). Freno a la expoliación: La experiencia de la Comissió de Patrimoni de la Societat Catalana d'Arqueologia. Revista de Arqueología, 115: 7-13.

Alay, J. C. (1991). Les activitats de la Comissió de Patrimoni de la Societat Catalana d'Arqueologia envers la protecció del Patrimoni Històric. En: Jornades sobre protecció legal del Patrimoni Arqueològic. Dossier d'Informació i Documentació pels municipis. Monogràfic 6. Diputació de Barcelona: 124-138.

Alay, J. C. (1994). Objetivo: sensibilización social. Revista de Arqueología, 155: 6-11.

Alay, J. C. (2000). L'Espoli arqueològic a Catalunya: el "furtivisme". Bases jurídiques i conceptuals. Tesis de licenciatura. Universitat de Barcelona. 107 págs. Inédita.

Alay, J. C. (2013). Preservació del Patrimoni Històric: Lexperiència de la Comissió de Patrimoni de la Societat Catalana d'Arqueologia. Auriga, 68 (Desembre 2013) -IX Fòrum Auriga, Ripoll 9-10 novembre 2013-: 60-64.

Alay, J. C. (2015). L'espoli arqueològic a Catalunya: Sistematització de la tipologia conductual dels furtius. Tesis doctoral. 538 págs. Universitat de Barcelona. Publicación digital: <http://hdl.handle.net/10803/ 396672>.

Alay, J. C. (2016). Els arqueo-furtius catalans. Felibrejada, Butlletí del Grup d'Història del Casal, Época 5a, Año XXI, 96 (2014-15: 31-47.

Alay, J. C. (2017). Los indicios forenses de las actividades furtivas en Arqueología terrestre. Gaceta Internacional de Ciencias Forenses, 22 (Enero-Marzo 2017): 10-31.

Alay, J. C. (2018). El arqueofurtivismo en Catalunya: una propuesta tipológica. En: El expoliar se va a acabar. Uso de detectores de metales y arqueología: sanciones administrativas y penales, coordinado por I. Rodríguez Temiño y A. Yáñez. Ed. Tirant lo Blanch. Valencia: 59-102.

Alay, J. C. y Clariana, J. F. (2018). El poblat ibèric de Burriac, entre el desconeixement social i l'oblit de les administracions. 11è Col-loqui Història a Debat.
Felibrejada, 97: 106-142. Grup d'Història del Casal de Mataró.

Alegre, J. M. (1994). Evolución y régimen jurídico del Patrimonio Histórico. Colección Análisis y Documentos, 5. Ministerio de Cultura. Madrid. Volumen I, 678 págs. y Volumen II, 806 págs.

Alfarás, R. (1894). Pesca de ánforas. Boletín de la Asociación Artístico-Arqueológica Barcelonesa, Año IV, Noviembre 1894, 40: 89-94.

Almagro-Gorbea, M. y Maier, J. (eds.) (2003). 250 años de Arqueología y Patrimonio. Documentación sobre Arqueología y Patrimonio Histórico de la Real Academia de la Historia. Estudio General e Índices. Real Academia de la Historia. Madrid. 520 págs.

Almagro-Gorbea, M. (2017). Un alabastrón del Pintor de Ampurias (Emporion Painter), de la antigua colección Montaner de Barcelona, relocalizado. Homenatge de Glòria Trias Rubiés. Cerámicas griegas de la península Ibérica: cinquanta anys després (1967-2017). Centro Iberia Graeca. Barcelona: 86-96.

Almansa, J. y Matas, F. J. (2018). Hacia una regulación de la Detección Metálica en Arqueología. Un paso adelante en un conflicto enquistado. En: El expoliar se va a acabar. Uso de detectores de metales y arqueología: sanciones administrativas y penales, coordinado por I. Rodríguez Temiño y A. Yáñez. Ed. Tirant lo Blanch. Valencia: 39-58.

Alonso, M. R. (1992). El Patrimonio Histórico. Destino público y valor cultural. Universidad de Oviedo - Ed. Civitas. Madrid. 454 págs.

Álvarez, J. L. (1989). Estudios sobre el Patrimonio Histórico Español. Ed. Civitas. Madrid. 897 págs.

AnTón, D. (2007). L'arqueologia d'alta muntanya en els Pirineus catalans occidentals. Estrat Crític, 1: 11-16.

Aznar, M. J. (2004). La protección internacional del patrimonio cultural subacuático con especial referencia al caso de España. Tirant Monografías, 337. Ed. Tirant lo Blanch. Valencia. 661 págs.

Balcells, M. (2018). Aspectos criminológicos del expolio y del tráfico ilícito del patrimonio arqueológico. En: El expoliar se va a acabar. Uso de detectores de metales $y$ arqueologia: sanciones administrativas y penales, coordinado por I. Rodríguez Temiño y A. Yáñez. Ed. Tirant lo Blanch. Valencia: 335-357.

Balmaseda, L. J. (1995a). El tesoro perdido de Guarrazar. Archivo Español de Arqueología, 68: 149-164.

BALMASEDA, L. J. (1995b). La reclamación diplomática del Tesoro de Guarrazar. Boletín de la ANABAD, 1/1995: 165-175. 
BALmasedA, L. J. (1996). Las versiones del hallazgo del tesoro de Guarrazar. Boletín del Museo Arqueológico Nacional, Tomo XIV, Homenaje a Mercedes Rueda Sabater "in memoriam": 95-110.

BARral, X. (1989). La història moderna del mosaic del Sacrifici d'Ifigènia d'Empúries. Empúries, 48-50 (1986-1989), vol. I: 94-99.

BARrero, C. (1990). La ordenación jurídica del Patrimonio Histórico. Ed. Civitas. Madrid. 735 págs.

Batista, R. (1963). Puig Lloses. En: Sepulcros megalíticos de la comarca de Vic. Corpus sepulcros megalíticos. Fascículo 2. Núm. 1. Instituto de Prehistoria y Arqueología de la Diputación de Barcelona.

Bellón, J. P. (2012). Exvotos en papel. Exvotos ibéricos (Núm. 2). El Instituto Gómez-Moreno, Fundación Rodríguez-Acosta (Granada). Instituto de Estudios Giennenses. Diputación Provincial de Jaén. Jaén: 59-75.

BELlón, J. P. (2013). La memoria sobre los santuarios iberos de Jaén. En: Santuarios Iberos: Territorio, ritualidad y memoria. Actas del Congreso El Santuario de la Cueva de La Lobera de Castellar 1912-2012. Ed. Asociación para el desarrollo rural de la Comarca de El Condado. Torredonjimeno: 57-78.

Blázquez, J. M. (1996), Los fenicios, transmisores de la cultura egipcia a Occidente". En: E. Acouaro (ed.). Alle soglie della Clasicità. Il Mediterraneo tradizione e innovazione. Studi in onore di Sabatino Moscati, vol. 2: Archeologia e Arte. Pisa-Roma: 547-557.

Bowman, B. (2011). Drugs, Arms, and Arrowheads: Theft From Archaeological Sites and the Dangers of Fieldwork Market in Antiquities. Journal of Contemporary Criminal Justice, volume 27, 4: 500-522. SAGE. DOI: $10.1177 / 1043986211418891$.

Buscató, Ll. y Pons, Ll. (2002). La troballa del mosaic del Sacrifici d'Ifigènia a Empúries i la seva posterior adquisició per la Comissió de Monuments de Girona. Uns fets poc coneguts. Empúries, 53: 195-209.

Buscató, Ll. (2011), De l'Antiquarisme a l'Arqueologia. La protecció del Patrimoni Històric i Arqueològic a la Província de Girona (1835-1876). Tesi doctoral. Universitat de Girona. 610 págs.

Campillo, J. y Romero, S. (2016). Espoli: del museu al jutjat. Les infraccions penals contra el patrimoni historicoartístic a Catalunya (1983-2015). Col-lecció Camí Ral núm. 38. Rafael Dalmau Editor. Barcelona. 135 págs.

CARrasco, R. (1991). La protecció legal del patrimoni cultural. Jornades sobre protecció legal del Patrimoni Arqueològic. Dossier d'Informació i Documentació pels municipis. Monogràfic núm. 6. Diputació de Barcelona. Barcelona: 11-31.
CERdì, C. (1991). La via administrativa: Balanç de la seva aplicació. En: Jornades sobre protecció legal del Patrimoni Arqueològic. Dossier d'Informació $i$ Documentació pels municipis. Monogràfic núm. 6. Diputació de Barcelona. Barcelona: 33-45.

Colominas, J. (1954). Sepultura de un alfarero-vaciador en la necrópolis del Puig dels Molins (Ibiza). En: I Congreso Arqueológico del Marruecos Español (22-26 junio 1953). Alta Comisaría de España en Marruecos y Delegación de Educación y Cultura. Tetuán: 191-197.

Contreras, V. (2018). Pasado, presente y futuro de la lucha contra el expolio arqueológico y cultural en Extremadura. En: El expoliar se va a acabar. Uso de detectores de metales y arqueología: sanciones administrativas y penales, coordinado por I. Rodríguez Temiño y A. Yáñez. Ed. Tirant lo Blanch. Valencia: 215-244.

Daniel, G. (1986). Historia de la Arqueología. (Edición original de 1966). Alianza Editorial. Madrid. 300 págs.

DAurA, A. (1983). Excavació arqueològica a Gargallà (Montmajor, Berguedà). Butlletí del Patronat Municipal de Museus, 2: 46-49.

Díaz-Andreu, M. y Ramírez, M. E. (2001). La Comisaría General de Excavaciones Arqueológicas (1939-1955). Complutum, 12: 325-343.

EnRíQuez, J. J. y GonzÁlez, F. (2005). Arqueología y Defensa del Patrimonio. La experiencia del Grupo de Delitos contra el Patrimonio Histórico de Extremadura. Complutum, 16: 33-57.

Escribano, C. y Del Val, J. (2018). Patrimonio arqueológico y expolio en Castilla y León. En: El expoliar se va a acabar. Uso de detectores de metales $y$ arqueología: sanciones administrativas y penales, coordinado por I. Rodríguez Temiño y A. Yáñez. Ed. Tirant lo Blanch. Valencia: 183-213.

Esteva, L. (1964). Bousarenys. En: Sepulcros megalíticos de las Gabarras (Gerona) I. Corpus sepulcros megaliticos. Fascículo 3. Núm. 2. Fichas 5 a 8. CSIC Barcelona- Servicio de Investigaciones Arqueológicas de la Diputación de Gerona.

FÁbrega, A. (2000). Llegendes de ponts, dòlmens $i$ menhirs a Catalunya. Itineraris. Col-lecció Popular Llegendes núm. 2. El Farell Edicions. Sant Vicenç de Castellet. 158 págs.

FERNÁNDEZ, F. (1996). De excavaciones clandestinas, mercado de antigüedades y publicación de hallazgos. Complutum Extra, 6 (II). Homenaje al Profesor Manuel Fernández-Miranda: 283-294.

Ganau, J. (1998). La protección de los monumentos arquitectónicos en España y Cataluña 1844-1936: legislación, organización e inventario. Universitat de Lleida. Lleida. 129 págs. 
García Calderón, J. M. (2016). La defensa penal del Patrimonio arqueológico. Ed. Dykinson. Madrid. 394 págs.

Gimeno, M., Iniesta, A., San Nicolás, M. y Santiuste, F. (1996). Curso de Protección del Patrimonio Arqueológico dirigido a los Cuerpos y Fuerzas de seguridad del Estado en Murcia. Celebrado en Murcia del 23 al 25 de mayo de 1994. Consejería de Cultura y Educación. Murcia. 117 págs.

Guasch, J. A. (2018). La Guardia Civil y su lucha contra el expolio arqueológico subacuático. En: El expoliar se va a acabar. Uso de detectores de metales $y$ arqueología: sanciones administrativas y penales, coordinado por I. Rodríguez Temiño y A. Yáñez. Ed. Tirant lo Blanch. Valencia: 409-437.

Guisasola, C. (2001). Delitos contra el patrimonio cultural: Artículos 321 al 324 del Código Penal. Ed. Tirant lo Blanch. Valencia. 782 págs.

Hernández, G. (1991). Consideracions sobre la protecció legal del Patrimoni Arqueològic arran del cas del Coll del Moro. En: Jornades sobre protecció legal del Patrimoni Arqueològic. Dossier d'Informació i Documentació pels Municipis. Monogràfic núm. 6. Diputació de Barcelona. Barcelona: 110-122.

Institut de Prehistòria i Arqueologia (ed.) (1980). Elogi de l'Acròpolis pel rei Pere el Cerimoniós. Informació Arqueològica, 33-34, Volumen VI: 88.

Junta de Castilla y León (ed.) (1997). Protección del Patrimonio Histórico. La Guardia Civil y la conservación de los bienes culturales. Jornadas celebradas en Ávila, junio 1997. Junta de Castilla y León. 272 págs.

Maier, J. (2003). La Comisión de Antigüedades de la Real Academia de la Historia. En: M. Almagro y J. MaIer (eds.). 250 Años de Arqueología y Patrimonio. Madrid: 27-51.

Mederos, A. y Escribano, G. (2006). Los inicios de la arqueología subacuática en España (1947-1984). Mayurqa, 31: 359-395.

Meyer, K. E. (1990). El saqueo del pasado. Fondo de Cultura Económica. Edición original norteamericana de 1973. México: 358 págs.

Molinero, M. A. (1995). Recipientes de piedra. En: $\mathrm{M}^{\mathrm{a}} \mathrm{J}$. López Grande et alii. Excavaciones Arqueológicas en Egipto, vol. II, Part II. Madrid: 204-278.

Montes, R. (1993). Falsificaciones arqueológicas en España. Ed. Algazara. Málaga. 173 págs.

Nieto, X. (2001). Arqueologia subaquàtica a Catalunya i legislació. Drassana, 9: 96-105.

NúÑEZ, E. y MuÑoz, J. (1988). Excavación en la necrópolis del Cerro de las Balas. Écija. Sevilla. En: Anuario Arqueológico de Andalucía 1988, III Actividades de urgencia. Consejería de Cultura y Medio Ambiente de la Junta de Andalucía. Sevilla: 429-433.
PADró, J. (1983). De nuevo sobre los hallazgos egipcios y egiptizantes en la Península Ibérica. Cuadernos de Prehistoria y Arqueología Castellonenses, 9 (1982-1983): 149-191.

Pellicer, M. (1962). Excavaciones en la necrópolis púnica "Laurita" del Cerro de San Cristóbal (Almuñécar, Granada). Excavaciones Arqueológicas en España 17. Ministerio de Educación Nacional. Madrid. 66 págs. y XX láminas.

Pellicer, M. (2007), La Necrópolis Laurita (Almuñécar, Granada) en el contexto de la colonización fenicia. Cuadernos de Arqueología Mediterránea. Vol. 15. Publicaciones del Laboratorio de Arqueología. Universitat Pompeu Fabra. Barcelona. 192 págs.

Pena, R. C. y Díaz, A. (2018). El expolio en Galicia en el marco legal del patrimonio arqueológico. En: El expoliar se va a acabar. Uso de detectores de metales $y$ arqueología: sanciones administrativas y penales, coordinado por I. Rodríguez Temiño y A. Yáñez. Ed. Tirant lo Blanch. Valencia: 245-262.

PÉrez, A. (2012). La proto-protección jurídica del patrimonio histórico español en la Edad Media y en la Edad Moderna. Anuario Facultad de Derecho, V (2012): 383-399.

Picón, A. (2018). Expolio arqueológico en Catalunya y la implicación del Cos d'Agents Rurals de la Generalitat de Catalunya. En: El expoliar se va a acabar. Uso de detectores de metales y arqueología: sanciones administrativas y penales, coordinado por I. Rodríguez Temiño y A. Yáñez. Ed. Tirant lo Blanch. Valencia: 103-130.

Pita, R y Díez-Cononel, L. (1968). La necrópolis de "Roques de San Formatge" en Seros (Lerida). Excavaciones Arqueológicas en España núm. 59. Ministerio de Educación y Ciencia. Madrid. 71 págs. y X láminas.

Quirosa, M. V. (2006). Historia de la protección de los bienes culturales muebles: definición, tipologías y principios generales de su estatuto jurídico. Servicio de Publicaciones de la Universidad de Granada. Granada. 419 págs.

RABADÁn, T. (2007). Protocol d'actuació en cas de delictes contra el Patrimoni Arqueològic i Paleontològic. Urtx, 20: 391-398.

RABADÁN, T. (2008). Las brigadas de patrimonio en el entorno jurídico de las Comunidades Autónomas. Mossos d'Esquadra. En: La lucha contra el tráfico ilícito de Bienes Culturales. Curso celebrado en Madrid los días 16-27 octubre 2006. Edición Pilar Barraca de Ramos y Ministerio de Cultura. Madrid: 101-105.

RAurich, X. (1994). El jaciment de Cala Cativa: notes sobre el primer treball d'arqueologia subaquàtica realitzat a Catalunya. Annals de l'IEE, 27: 262-271.

Renart, F. (2002). El delito de daños al patrimonio cultural español. Análisis del art. 323 del Código Penal 
de 1995. Ed. Comares. Estudios de Derecho Penal núm. 36. Granada: 499 págs.

Rodrigo, J. J. (1991). La protecció del Patrimoni des d'una perspectiva policial. En: Jornades sobre protecció legal del Patrimoni Arqueològic. Dossier d'Informació $i$ Documentació pels municipis. Monogràfic 6. Diputació de Barcelona. Barcelona: 140-144.

Rodríguez Díaz, A., Ortíz, P., Pavón, I. y Duque, D. M. (2014). El tiempo del tesoro de Aliseda. I Historia e historiografía del hallazgo. Ed. Tagus. Cáceres.

Rodríguez Díaz, A., Duque, D. M. y Pavón, I. (2015). El tesoro de Berzocana: los rastros del hallazgo. Norba. Revista de Historia, vol. 27-28 (2014-2015): 21-61.

Rodríguez Temiño, I. (1998). La actuación contra el expolio del Patrimonio Arqueológico en Andalucía. $S P A L, 7: 25-43$.

Rodríguez Temiño, I. (2000). Los detectores de metal y el expolio del Patrimonio Arqueológico. Algunas propuestas de actuación en Andalucía. PH Boletín del Instituto Andaluz del Patrimonio Histórico, 30: 32-49.

Rodríguez Temiño, I. (2003). El uso de los detectores de metales en la legislación cultural española. Patrimonio Cultural y Derecho, 7: 233-259.

Rodríguez Temiño, I. (2012). Indiana Jones sin futuro. Ed. JAS Arqueología. Madrid. 445 págs.

Rodríguez Temiño, I. (2017). Propuesta para la valoración de daños en yacimientos arqueológicos. Curso Delitos contra el patrimonio histórico. Especial referencia al patrimonio arqueológico, 29 y 30 de junio 2017. Centro de Estudios Jurídicos. Madrid. 21 págs.

Rodríguez Temiño, I., Yáñez, A., Jorge, S., Reyes, A., Rufino J., Salas, J. y Lavín, A. C. (2018). Arqueometría forense aplicada al tráfico ilícito de antigüedades: un proyecto de investigación en el límite del conocimiento. En: C. Guisasola Lerma (ed.). Expolio de Bienes Culturales. Instrumentos legales frente al mismo. Ed. Tirant lo Blanch. Valencia: 268-296.

Rodríguez Temiño, I. (2019). Assessing Damage to Archaeological Heritage in Criminal and Administrative Proceedings. Heritage, 2019, 2: 408-434.
Romeo, F., Royo, J. I., Gonzalvo, I., Fatás, L. y Angas, J. (2017). Un nuevo sistema para la valoración económica de los daños en yacimientos arqueológicos expoliados. Revista Patrimonio Cultural y Derecho, 21: 231-267.

Rueda, C. (coord.) (2012). Exvotos ibéricos (Núm. 2): El Instituto Gómez-Moreno, Fundación RodríguezAcosta (Granada). Instituto de Estudios Giennenses. Diputación Provincial de Jaén. 332 págs.

Ruiz, A. y RuedA, C. (2014). Los exvotos de bronce del Farmm: oppida y santuarios. FARMM, Fondo Arqueológico Ricardo Marsal Monzón. Consejería de Educación, Cultura y Deporte. Junta de Andalucía. Sevilla: 131-144.

Sánchez, M. L. (2002). El santuario del Cerro de los Santos (Montealegre del Castillo, Albacete). Nuevas aportaciones arqueológicas. Instituto de Estudios albacetenses "Don Juan Manuel" de la Excma. Diputación de Albacete, Serie 1 Estudios - Núm. 136. Biblioteca Digital de Albacete “Tomás Navarro Tomás”. Albacete. 316 págs.

Soler, J. M. (1982). Los tesoros de Villena. Historia 16, Año VII, 73 (mayo 1982): 121-128.

Tarradell, M. y Font, M. (1975). Eivissa Cartaginesa. Ed. Curial. Barcelona. 316 págs.

Tortosa, T. y Mora, G. (1996). La actuación de la Real Academia de la Historia sobre el Patrimonio Arqueológico: Ruinas y Antigüedades. Archivo Español de Arqueología, 69: 191-217.

Velázouez, F. (2002). Un vaso con representación de Bes en la península ibérica. SPAL, 11: 107-119.

VIVAR, G. (2012). Memòria de la Carta Arqueològica subaquàtica de la comarca de l'Alt Empordà (2011). CASC Museu Arqueològic de Catalunya. Girona. 24 págs.

YáñEz, A. (2018). Patrimonio arqueológico y derecho sancionador. Ed. Tirant lo Blanch. Valencia. 284 págs.

YÁñez, A. y Rodríguez Temiño, I. (eds.) (2018). El expoliar se va a acabar. Uso de detectores de metales y arqueología: sanciones administrativas y penales. Ed. Tirant lo Blanch. Valencia. 532 págs. 